\title{
THE TRANSFORMATIVE EXPERIENCE OF DRAMA AND PERFORMANCE ART WITH SURVIVORS OF GENDER-BASED VIOLENCE
}

\author{
by \\ Michelle Crozier, BA, University of Waterloo, 2014 \\ BSW, University of Waterloo, 2015 \\ An MRP \\ Presented to Ryerson University \\ in partial fulfillment of the \\ requirements for the degree of \\ Master of Social Work \\ in the Program of \\ Social Work
}

Toronto, Ontario, Canada, 2018

(C) Michelle Crozier, 2018 


\section{AUTHOR'S DECLARATION FOR ELECTRONIC SUBMISSION OF AN MRP}

I hereby declare that I am the sole author of this MRP. This is a true copy of the MRP, including any required final revisions.

I authorize Ryerson University to lend this MRP to other institutions or individuals for the purpose of scholarly research.

I further authorize Ryerson University to reproduce this MRP by photocopying or by other

means, in total or in part, at the request of other institutions or individuals for the purpose of scholarly research.

I understand that my MRP may be made electronically available to the public. 


\begin{abstract}
.
The Transformative Experience of Drama and Performance Art with Survivors of Gender-Based Violence

Master of Social Work, 2018

Michelle Crozier

Program of Social Work, Ryerson University
\end{abstract}

This qualitative research study strives to understand the transformative process of drama and performance art through the lived experiences of survivors of gender-based violence. Inperson interviews explore the narratives of three survivors that have accessed drama and performance art in a variety of settings such as community theatres, educational institutions, and online forums such as YouTube. This interpretive phenomenological methodology is grounded in an Anti-Oppressive, intersectional transfeminist theoretical framework. The research explores the following question: What is the unique experience of drama and performance art when accessed by survivors of gender-based violence? This research offers an opportunity to hear from survivors about the potential of drama and performance art to facilitate healing and connection to community, while allowing survivors to understand their trauma. The intended outcome of this research project will be an empathetic understanding into the unique experience of drama and performance art when conducted with survivors of gender-based violence. The primary purpose of this research is to provide additional knowledge into the potential of drama and performance art in the field of Anti-Oppressive Social Work Practice, specifically when supporting survivors and resisting gender-based violence. 


\section{ACKNOWLEDGEMENTS.}

I would like to take this opportunity to thank a number of people, who's support allowed for this research project to be possible. Thank you to the Ryerson University Social Work Professors who have provided me with critical knowledge and guidance throughout this research process. Thank you to my dear classmates (and friends) for your continuous words of encouragement and support, which created a community where meaningful learning was possible. To my wonderful friends and family for holding me compassionately throughout every challenging step of this process. Lastly, thank you to participants Amy, Devon and Sheela (pseudonyms), without whose vulnerability in sharing unique lived experiences this research paper would not have been possible. 


\section{DEDICATION.}

This Major Research Paper is dedicated to my Gramma, Johanna, and Mother, Lauri. Thank you both for continuously supporting my exploration of this "drama stuff”. Your vulnerability, resilience, strength, and love has guided my passion and motivation for this field of research. I additionally dedicate this to all survivors of gender-based violence. May we continue to work together towards creatively changing the world with art. 


\section{TABLE OF CONTENTS.}

Chapter 1: Introduction

Chapter 2: Theoretical Framework

p. 5

Personal epistemology

Anti-Oppressive Social Work Practice

Intersectionality

Transfeminism

Chapter 3: Literature Review

Gender-based violence

Drama and performance art

Theatre of The Oppressed \& Art as Activism

Chapter 4: Methodology

p. 37

Interpretive Phenomenology Analysis

Subject positioning

The Study

Recruitment

Sampling and Criteria for Selection

Data Collection

Coding

Profile of Participants

Chapter 5: Findings

p. 48

Gender-based violence: Power imbalance, gender norms/expectations.

Barriers in support seeking: invalidation, shame, fear.

Experience of drama and performance art: empowerment, representation, coping skills, connection to self and others.

Drama and social change.

Chapter 6: Discussion

p. 68

Personal Statement (bracketing)

Limitations

Chapter 7: Implications \& Conclusion

p. 76

Appendices

p. 79

References

p. 96 


\section{LIST OF APPENDICES.}

$\begin{array}{lr}\text { Appendix A: Recruitment Flyer } & \text { p. } 79\end{array}$

$\begin{array}{ll}\text { Appendix B: Email and Facebook Recruitment } & \text { p. } 80\end{array}$

$\begin{array}{ll}\text { Appendix C: Consent Form } & \text { p. } 81\end{array}$

$\begin{array}{ll}\text { Appendix D: Interview Guide } & \text { p. } 86\end{array}$

$\begin{array}{ll}\text { Appendix E: Resources for Participants } & \text { p. } 92\end{array}$

Appendix F: Ethics Approval Certificate p. 94 


\section{INTRODUCTION.}

"Theatre is a form of knowledge; it should and can also be a means of transforming society. Theatre can help us build our future, rather than just waiting for it."- Augusto Boal, 2005, p. 16

The following Major Research Paper is a step toward connecting the experience of drama and performance art to the social issue of gender-based violence. While these two topics have been explored separately, when viewed together they have the potential for contributing to AntiOppressive Social Work Practice. Throughout this qualitative research project, I use interpretive phenomenology to explore the potential of drama and performance art to respond and resist gender-based oppression. The purpose of this research project is to give voice and space to survivors of gender-based violence and understand their experience in accessing drama and performance art.

Experiences of violence have devastating impacts on individuals, families, communities and society as a whole. Gender-based violence is a result of an unequal society, which functions as a barrier to achieving gender-equality (Status of Women Canada, 2017). The terms genderbased violence and violence against women are frequently used interchangeably to describe the disproportionate abuse, power and control over another person based on their gender identity, gender expression, or perceived gender (Status of Women Canada, 2017). I will not be using these terms interchangeably throughout this paper. I do this intentionally because gender-based violence is experienced by many people that do not identify as cis-women, including a number of participants interviewed in this research study.

Gender-based violence includes any acts of violence or abuse that result in physical, sexual, emotional, financial and mental harm or suffering (Status of Women Canada, 2017). 
Calton, Cattaneo \& Gebhard (2016), discuss how different acts of violence occur within all levels of society and are based on larger systems of oppression. These systems of oppression function to give men more social, political, and economic power than women (Calton, Cattaneo \& Gebhard, 2016). As a result, there is a cultural belief that it is natural for men to have power and control over women within romantic relationships, enacting this societal belief within relationships (Calton, Cattaneo \& Gebhard, 2016).

Research conducted with survivors of violence demonstrates positive impacts of drama and performance art techniques. Findings indicate drama provides a creative outlet where participants could process their experiences of violence, while strengthening the relationship with oneself and others (Carbonell \& Parteleno-Barehmi, 1999; Frisina, 2010; Jarman, 2014; Kirk, 2015; Mackenzie, 2013; Rousseau et al., 2007; Testoni et al., 2015). Common themes in this literature revealed that when people participated in drama and performance art they experienced an increase in self-esteem, self-awareness, and connection to others (Dix, 2015; Frisina, 2010; Jarman, 2014; Kirk, 2015; Mackenzie, 2013; Oon, 2010; Orkibi et al., 2014; Rousseau et al., 2007). Creative therapies provide an alternative method of processing difficult experiences, such as trauma and violence, that transcend traditional methods of communication (Emunah, 1994). Drama and performance art utilize interactive techniques that can be used in a group or individually and can include: writing and learning scripts, role play, improvisational exercises, mime, spoken word, dance/movement, poetry and using props such as puppets or masks (Emunah, 1994).

Drama techniques are also used to challenge oppression, including social issues such as gender-based violence. Augusto Boal's Theatre of the Oppressed is an applied theatre form using improvisation and audience participation to explore social issues (Brigell, 2010; Giesler, 2017; 
Midha, 2010; Saeed, 2015; Shawyer, 2011; Stahl, 2018). Augusto Boal, theatre director and activist, rejected the idea that theatre could only be enjoyed by the upper class and started working with oppressed communities for the purpose of liberation and transformation (Brigell, 2010; Giesler, 2017; Midha, 2010; Saeed, 2015; Shawyer, 2011; Stahl, 2018). Boal believed that individual problems originate from societal oppression and that theatre could be used to address and connect all of these levels (Brigell, 2010; Midha, 2010). Theatre techniques have skills applicable to the fields of development, social work, education, politics, and the fine arts (Shawyer, 2011).

Values embedded within Theatre of the Oppressed align with Anti-Oppressive Social Work Practice, through using drama techniques to challenge oppression dismantle oppressive structures that function to marginalize people (Bains \& Edwards, 2015; Wong \& Ying Yee, 2010). Further research on understanding the potential of drama and performance art will contribute to Anti-Oppressive Social Work Practice. If Anti-Oppressive Social Work is to move forward and disrupt the institutions that keep people immobilized through gender-based violence, it is important to consider the potential of alternative methods of healing and resisting oppression (Bains \& Edwards, 2015; Wong \& Ying Yee, 2010).

Within this Major Research Paper, I expand on pre-existing research focusing on drama and performance art conducted with survivors of gender-based violence and its potential for contributing to social change. This qualitative research study incorporates a theoretical framework informed by Anti-Oppressive Social Work Practice, intersectionality, and transfeminism in discussing and understanding survivor's unique experiences of drama and performance art. The research question used to guide this project is: What is the unique experience of drama and performance art when accessed by survivors of gender-based violence? 
I begin with a discussion of the theoretical frameworks that will be used to guide this research project. This section includes a review of Anti-Oppressive Practice, intersectionality and transfeminism. I access these theories to provide a critical lens in viewing research literature and analyzing the data collected from interviews in this research project. Following this, I move into a review of the research literature to provide a context for this research study to build upon. The literature includes a review of gender-based violence and how gender-based violence will be critically understood throughout this research study. In addition, I review literature conducted on drama and performance art in a variety of settings, exploring techniques of dramatherapy, psychodrama, and theatre of the oppressed with diverse populations.

My methodology chapter includes my rationale for using interpretive phenomenology to guide this research project. Within the methodologies chapter I explain my personal connection and subject positioning to this research inquiry, including my assumptions, values and biases. I describe details of the research study, including recruitment, confidentiality, and the coding process used to understand the data. Following this section, I move into the findings discovered from the interviews with participants, highlighting major themes within the data, and the implications this has for Anti-Oppressive Social Work Practice. 


\section{CHAPTER 2. THEORETICAL FRAMEWORK}

In this chapter, I outline and describe my theoretical framework, as well as my reasoning for using this framework as a lens to conduct my research. My theoretical framework incorporates an intersectional, transfeminist, Anti-Oppressive Social Work approach to collecting, interpreting and analyzing data. Each one of these theories will guide my research by creating a foundation where I can critically understand the social issue of gender-based violence, how this connects to participants and their experiences of drama and performance art. To gain an understanding of what makes the process of drama and performance art unique for survivors, it is crucial that I understand the social problem of gender-based violence from these theoretical frameworks to ensure the nuances of participant's experiences. In doing this, I hope to recognize the unique process of drama and performance for survivors through understanding and linking these experiences. I use these frameworks to reflect on my own social positioning within this chapter and throughout this research paper. I first define each framework and then move into an explanation as to why I have chosen each. Each theoretical framework is discussed in depth as it informs each step of the research process.

\section{Personal epistemology:}

Interpretive phenomenology guides my exploration of understanding the transformative experience of drama and performance art with survivors of gender-based violence. Therefore, my personal epistemology will naturally influence the way I understand this phenomenon (Creswell \& Poth, 2018). In this section I discuss my own personal values, assumptions, and experiences in relation to gender-based violence and drama. I explain how I use the practice of critical reflection to unsettle and challenge the way that I have learned to value and construct knowledge (Fook \& Gardner, 2007). 
Hunter (2002), explains that epistemologies do not exist outside of people, rather epistemologies are accessed numerous times for people to understand their world. Epistemological thinking is not exclusive to educational settings but is a critical component of lifelong learning (Hofer, 2001). Understanding one's epistemology allows individuals to evaluate new information, competing knowledge claims, and make decisions that affect their lives and others (Hofer, 2001). One's personal epistemology is their beliefs about knowledge and how they come to construct knowledge (Arnd-Caddigan, Averett \& Pozzuto, 2010).

Fook \& Gardner (2007) describe the unsettling process of critical reflection, which is a theory and a process that allows one to unearth their social assumptions, including thoughts, actions and emotions. The process of critical reflection is unsettling because it challenges writers into unfamiliar territories and to analyze issues from different perspectives (Fook \& Gardner, 2007). Through this section I uncover my personal values, experiences, and assumptions about gender-based violence and drama. In this continuous process of critical reflection, I illuminate my personal epistemology and how it impacts each stage of this research.

My personal epistemology has developed out of my identity, education, and personal and professional experiences within Canadian society (Baksh, 2016). My research inquiry is close to my identity. The motivation that guides my research is both personal and professional. My personal motivation to research drama and performance art with survivors of gender-based violence was conceived through my own experiences of both gender-based violence and participation in drama. In understanding and owning my identity as a cis-white queer female survivor of violence, I developed a strong passion for combating gender-based violence both in my personal life and professional identity as a social worker. In my personal journey of healing 
from the violence I experienced, I struggled to access professional support settings due to feelings of confusion, isolation, guilt, and shame. When I did reach out for professional support, the experience was judgemental and unsupportive, which only increased the negative feelings I carried.

Drama and performance art within the classroom setting became as a safe outlet for me to understand my experiences, express difficult emotions, gain self-esteem and create relationships with others during a time when I felt completely isolated. Engaging in drama techniques allowed for me to build the skills and confidence I needed to resist gendered oppression in my daily life. Through a process of stepping into the life of another character, I was given a creative opportunity to escape myself and live out my emotions through another person. Within the experience of embodying a character, I was able to safely explore emotions or reactions through role playing, which did not feel safe in my own life. This process not only made uncomfortable emotions such as anger, sadness, and frustration easier to feel on a daily basis, but readily available to use constructively for my own empowerment.

Through having the opportunity to embody complex characters that were male, female, and non-gendered, I felt released from the confines of daily gender norms and expectations. I connected to parts of myself that were neglected or suppressed. Furthermore, participating in drama allowed for me to connect with others and build relationships in unique ways through the experience of role-play and story-telling. I met people who shared similar experiences to my own and left feeling less isolated in my daily life. Using a platform of drama, our group discussed social issues, such as gender-based violence, and creatively explored these issues through our characters. Through my experience, I realized the potential of drama in resisting gender-based 
violence to move toward social change. I wondered how many survivors were using drama and performance art to respond to their experiences of gender marginalization and oppression.

My personal epistemology in viewing drama and gender-based violence has been further shaped in my professional experiences as a social worker supporting trans, queer and female survivors of violence in both group home and crisis shelter settings. In my work experience, I recognized how the current responses, policies and practices available for survivors of violence frequently reinforce a cis-white, heterosexual middle-class female experiences of violence. Survivors were given a timeline of eight weeks to stay in shelter with their families and in this short time were encouraged to access individual and group therapy sessions, which would assist in extending their stay in shelter. The short time frame in shelter acted as a barrier particularly for women who were lower class, racialized, or immigrant and refugees, and women with disabilities, mental health, gambling and substance use concerns. Although the therapeutic model provided support to some survivors, it acted as a barrier for many survivors with complex identities who did respond or struggled to participate in these methods of therapy. For example, women with disabilities and women who arrived as immigrants, refugees, or whose first language was not English struggled to participate in counselling where connection was made verbally.

In both the shelter and group home setting I witnessed homophobia, transphobia and racism among various staff. I witnessed staff maintain spaces primarily for cis-women, attribute violence to race, and struggle with understanding experiences of non-heterosexual survivors. As a new staff, this influenced my level of comfort in sharing my identity as a queer survivor of violence and therefore my ability to support survivors in this environment. I reflected on my own positive experience of drama and its potential to provide a creative platform that could reduce 
some of these barriers, where staff and survivors could creatively connect and find new ways to challenge the gendered violence they experience on a daily basis.

Epistemologies are socially positioned within historical and political contexts (Hunter, 2000). There is social influence on the individual experience, and when research assumptions are unsettled, they can be transformed into ways that create social change (Fook \& Gardner, 2007). The knowledge I carry regarding gender-based violence and drama is largely shaped by my experiences as a cis-white able-bodied settler female social worker within Canadian society. My social positioning has influenced the way I understand and experience social work, gender-based violence, and drama. I experience privilege in my identity as a cis-white female, as I am frequently accepted into spaces where many racialized, disabled, trans and queer survivors are not. My womanhood has never been questioned. I do not experience the double layer of oppression from both racism and sexism that racialized women face on a daily basis, which can act as a barrier to seeking support. In understanding that intersections of race, gender, and sexuality influence the violence people face, this means it will impact the way people experience drama.

Therefore, I am critical of my personal beliefs and assumptions surrounding gender-based violence and drama and performance, as these are frequently affirmed by social structures in society because of my privilege as a cis-white woman (Baffoe, Asimeng-Boahene, \& Ogbuagu, 2014). I have utilized a variety of techniques that have demanded continuous critical reflection throughout this research process. I incorporated theoretical frameworks of intersectional, transfeminist, Anti-Oppressive Social Work Practice as a critical lens to aid in challenging my own biases and assumptions. I reviewed literature focusing on gender-based violence and drama that centers the experiences of people with complex identities. In my interviews with 
participants, I asked open-ended questions, where participants can share their experiences in their own time and words. Participants stories direct the interview and the questions act as a guide to for both myself and the participants. In each interview I clarified my understanding of each participants experiences to ensure I interpreted their stories accurately. Following each interview, I critically reflect on my own interpretations of participant responses through the process of journaling and memoing my thoughts within each interview transcript. I provide rationale for why I have highlighted specific quotes within both the methodology, findings, and discussion section of this paper.

\section{Anti-oppressive social work practice:}

A challenging learning opportunity throughout this research project was understanding how I would conduct and embody critical Anti-Oppressive research. Anti-Oppressive Practice (AOP), is a form of social justice oriented social work theory and practice (Bains \& Edwards, 2015; Wong \& Ying Yee, 2010). Anti-Oppressive approaches in social work developed as a response to struggles faced by marginalized groups to challenge oppressive power structures (Sakamoto \& Pitner, 2005). It is an approach to understanding the complexities of society’s social problems and used to recognize experiences of multiple oppressions to respond to the need to transform all levels within society (Bains \& Edwards, 2015; Sakamoto \& Pitner, 2005; Wong \& Ying Yee, 2010). Anti-Oppressive Social Work Practice is used as an umbrella term for a number of different approaches to social-justice oriented social work including Indigenous, feminist, anti-colonial and anti-racist (Bains \& Edwards, 2015; Sakamoto \& Pitner, 2005; Wong \& Ying Yee, 2010).

I use an Anti-Oppressive lens within this research study to contextualize survivor's individual experiences within the social problem of gender-based violence and connect this to 
the process of participating in drama. Within social work practice, research and literature, the focus is often on the issue within the context of the individual (Bains \& Edwards, 2015; Sakamoto \& Pitner, 2005). While it is valuable to gain an in-depth understanding of an individual's experience, failing to contextualize these experiences within social problems does not acknowledge the oppressive situations people respond to on a daily basis (Bains \& Edwards, 2015; Wong \& Ying Yee, 2010). Overall, this leads to an understanding of a social problem within an individual's behavior, rather than striving to transform oppressive structures in society that continue to produce these experiences for people (Bains \& Edwards, 2015; Wong \& Ying Yee, 2010). Through integrating Anti-Oppressive Practice within my theoretical framework, I am better equipped in understanding how participants' individual experiences are socially constructed (Sakamoto \& Pitner, 2005).

Anti-Oppressive Practice brings attention to the structural basis of societal privilege, oppression and recognizes the existence of multiple and intersecting identities (Baines, 2017). This framework provides a critical lens to this research, which highlights power imbalances within society that function to marginalize people through issues such as gender-based violence (Wong \& Ying Yee, 2010). Where oppressive power exists, there is also resistance (Vinthagen \& Johansson, 2013). There is power within survivor's stories of resistance, which is best understood situated in time, space and social relations (Vinthagen \& Johansson, 2013). In understanding the dominant power governing Canadian society as patriarchal, capitalist, white, and colonial it provides the context from which resistance of gender-based violence can be understood (Suzack, 2015).

When people experience gender-based violence, they develop unique skills and resources to survive. This research project focuses on how and when participants have accessed drama and 
performance art to resist and survive experiences of gender-based violence to transform their lives. Research findings illuminate experiences of both oppression and resistance in survivor's stories. Through understanding the struggle of power and resistance in the lives of survivors, I will better understand the potential capacity of drama to resist and challenge power (Vinthagen \& Johansson, 2013).

Sakamoto \& Pitner (2005), discuss the use of critical consciousness in Anti-Oppressive Social Work Practice to challenge social workers to be aware of existing power differentials and how this may inadvertently create an oppressive experience. Throughout this research process I use Anti-Oppressive techniques of critical reflection to interrogate my identity and continuously reflect on my own assumptions and biases to remain conscious of my social location (Sakamoto \& Pitner, 2005).

Overall, utilizing an Anti-Oppressive framework, I have a lens from which I can critically understand the context of survivor's experiences and how they use drama to harness power and resistance in their daily lives. I recognize the existing social structures that function to marginalize people based on intersecting identities such as race, gender identity and sexuality (Bains \& Edwards, 2015; Sakamoto \& Pitner, 2005; Wong \& Ying Yee, 2010). I incorporate this framework in my review of the literature, methodologies, interviews and discussion of the research findings. I critically understand the intersections of oppression and privilege within participants identities and how this impacts their experiences as survivors accessing drama (Baines, 2017). 


\section{Intersectionality:}

In addition to Anti-Oppressive Practice, a theoretical lens of intersectionality will be used to guide this Major Research Paper. Intersectionality is beneficial to this research project because it provides a theoretical perspective where I can understand the many components of participants identities and how this constructs their social experiences within society (Fook \& Gardner, 2007). In understanding that people experience violence differently based on intersections of their identity such as class, race, sexuality and gender, I have asked participants demographic questions to understand how intersections of their identity impact their experiences of violence, and participation in drama. An intersectional lens to this research allows for representation of the many ways people experience both gender-based violence and drama in the review of the literature, methodologies, and interviews with participants.

In the context of the issue of gender-based violence, survivor's acts of resistance are shaped by the power existing in relationships within the intersections of race, class, gender, sexuality and ability (Crenshaw, 1993; Vinthagen \& Johansson, 2013). Resistance is a practice which needs to be understood as intersectional because resistance engages with multiple forms of power and oppression (Vinthagen \& Johansson, 2013). The practice of resistance includes how people act in their daily lives to defy the dominant power, which is not as easily recognized because it is often quiet and seemingly invisible (Vinthagen \& Johansson, 2013). A theoretical lens of intersectionality opens perspectives on what resistance might be. In viewing categories such as gender, race and sexuality, relationships of power and privilege within societal structures can be better understood (Vinthagen \& Johansson, 2013). For example, to be in the social position of a white woman in Canadian society lessens one's power because of their gender; but 
to be a racialized woman in Canada society creates an additional barrier of oppression due to race (Vinthagen \& Johansson, 2013).

Intersections of a survivor's identity impact the way they experience and understand their social world. A theoretical lens of intersectionality provides a lens to this research project that encourages an understanding of how participating in drama impacts the lives of participants with complex identities. Moreover, this theoretical lens assists in recognizing how drama and performance art allows survivors to practice different forms of resistance in their daily lives, in ways they may not have been comfortable with prior to drama. Overall, this can provide insight into how drama techniques are used by survivors to resist gender oppression.

\section{Transfeminism:}

My reasoning for selecting a transfeminist theoretical framework was inspired through reading Oparah's (2010) article, which explores violence that transgender, gendernonconforming and queer people face every day. Oparah's article shifted the way I view and understand the social problem of gender-based violence within society. Prior to starting the Master of Social Work program, my understanding of gender-based violence was developed primarily from the experiences of white cis-women. After reading Oparah's (2010) article I felt unsettled by my guilt in realizing my narrow perspective of this social issue. I recognized my narrow understanding functions to perpetuate violence experienced by the LGBTQ community. In reconceptualizing the many ways people with complex identities can experience gender-based violence, I believe transfeminism provides an invaluable lens to this research project.

Koyama (2001) describes transfeminism as "primarily a movement by and for trans women who view their liberation to be intrinsically linked to the liberation of all women and 
beyond" (p. 1). Transfeminism is not exclusive to people that identify as trans-women, rather it is inclusive to all people that believe the liberation of trans women is tied to their own (Koyama, 2001). Due to the social, political and cultural structures that exist within Canadian society, trans women in particular frequently need to prove their womanhood and that their safety and wellbeing is contingent on whether they can "pass" for a "natural" woman (Koyama, 2001). As a result, the extreme forms of sexual violence experienced by trans women challenge feminist assumptions about patriarchal violence that frequently equate male genitalia with male privilege and power (Oparah, 2010).

Throughout history, there has been a failure of feminism to interrogate race, gender, sexuality and the vastly different experiences of oppression due to these intersections (Crenshaw, 1993). As a result, this means strategies of resistance within feminism frequently replicate and reinforce oppressive structures (Crenshaw, 1993). In second wave feminism, feminists focused on creating space for women and girls. Although this made strides in feminist thought, it failed to interrogate the category of "woman" as a stable foundation that is fixed rather than fluid, reinforcing the gender binary (Oparah, 2010). This failure of feminism to incorporate perspectives such as queer theory or antiracism while challenging the patriarchy means reproducing the subordination of queer and racialized women (Crenshaw, 1993). Feminism creating this concept of "woman only" spaces and "woman born woman" disregards the fluidity and complexity of gender identity and therefore people's experiences of gender-based violence (Oparah, 2010).

Third-wave feminism established a new understanding of the power of women through popular culture, and new technologies for communication, claiming of a positive sexuality open to complex identities and experiences (Espineira \& Bourcier, 2016). Transfeminism contributed 
to third-wave feminism by creating space and demanding for accountability of feminism to be inclusive of trans experiences. These efforts demanded feminism to rethink how marginalization can occur within feminism, particularly towards trans and queer people, and reorganize to include their experiences (Espineira \& Bourcier, 2016).

Throughout this research study I incorporate principles of transfeminism as a theoretical lens to conduct research (Oparah, 2010). The primary principles that guide transfeminism are that every individual has a right to define their own identities and make decisions about their own bodies (Koyama, 2001). Transfeminism advocates that people should have the freedom to express their gender without fear, violence or discrimination. I view the social issue of genderbased violence through a transfeminist lens in highlighting the experiences of LGBTQ survivors. Transfeminism provides a critical perspective to this research in understanding how people are confined by gender norms and expectations, while supporting the many ways a person can identify as woman (Koyama, 2001). I will unpack survivor's understanding of their sexuality and gender identity, and the process of participating in drama to understand the capacity of drama and what makes the experience unique for survivors. 


\section{CHAPTER 3. LITERATURE REVIEW}

This major research paper contributes to the existing literature viewing the potential of drama and performance art with survivors of gender-based violence. I begin with an introduction and explanation of what gender-based violence is and the many forms it can take within different societies throughout the world. Following a discussion of gender-based violence, I explain how it is framed within this research project from an intersectional, transfeminist Anti-Oppressive Social Work framework. Following a discussion of gender-based violence I connect this to research literature on drama and performance art. I specifically highlight research articles on dramatherapy, psychodrama, and Augusto Boal's theatre of the oppressed. This literature review will provide a context of what this Major Research Paper contributes to in understanding the transformative experience of drama and performance art with survivors of gender-based violence.

\section{Gender-based violence:}

The terms gender-based violence and violence against women are often used interchangeably, but are not synonymous (Terry \& Hoare, 2007). Under the UN General Assembly Declaration on the Elimination of Violence Against Women, gender-based violence includes violence within relationships, families, community, and systemically (Sommer, MuñozLaboy, Williams, Mayevskaya, Falb, Abdella, \& Stark, 2018). Gender-based violence occurs in all societies and includes any acts of violence or abuse that result in physical, sexual, emotional, financial and mental harm or suffering (Lundell, Eulau, Bjarneby, \& Westerbotn, 2018; Russo \& Pirlott, 2006; Status of Women Canada, 2017; Terry \& Hoare, 2007). 
Gender-based violence is a term used to describe violence that occurs as a result of the social norms and expectations attributed to each gender, in addition to the unequal power relationships between the two genders (Russo \& Pirlott, 2006; Terry \& Hoare, 2007; UNFPA \& WAVE, 2011). Existing gender norms around behavior and violence are internalized and reproduced in relationships through submissive femininity and dominant masculinity (Sommer et al., 2018). This occurs within intimate relationships, families, and communities, further legitimized by social policies (Sommer et al., 2018). Therefore, gender-based violence is not an issue women face randomly, but a problem affecting them because of their gender (Terry \& Hoare, 2007; UNFPA \& WAVE, 2011).

An analysis conducted by the World Health Organization in 2013 used data from over 80 countries and discovered that worldwide one in three women, or thirty five percent of women, have experienced physical and/or sexual violence (World Health Organization, 2017). This statistic speaks to a social issue that exists within and outside of Canada that has long term impacts on survivors (Russo \& Pirlott, 2006). The wide-spread prevalence and impacts of these various forms of violence communicates a woman's social positioning in society (Colarossi, 2005). Violence against women is not only a demonstration of sex inequality, but it exists to maintain an unequal balance of power (Watts \& Zimmerman, 2002).

Gender-based violence occurs in all societies and all stages of a woman's life cycle. Many women experience multiple episodes of violence, which can occur before they are even born, such as sex-selective abortions, and continue through childhood to adulthood and old age (Terry \& Hoare, 2007; UNFPA , \& WAVE, 2011). Gender-based violence arises from and maintains power imbalances between men and women, both as individuals and in groups (Russo \& Pirlott, 2006; Sommer et al., 2018; Terry \& Hoare, 2007). Overall, this violence poses serious 
threats to the lives of women worldwide and is particularly prominent in conflict-affected communities and displaced populations (Sommer et al., 2018).

The World Health Organization recognizes gender-based violence as an important public health issue (Colarossi, 2005; Russo \& Pirlott, 2006; Terry \& Hoare, 2007; World Health Organization, 2017). Gender-based violence is a persisting social problem within society, rather than an individual, mental health, or family issue, which has long-term substantial physical, social and economic costs (Colarossi, 2005; Edwards et al., 2016; Russo \& Pirlott, 2006; Statistics Canada, 2013; Status of Women Canada, 2017). There are many consequences resulting from gender-based violence and the people primarily impacted by this issue are women and adolescent girls (Terry \& Hoare, 2007; UNFPA \& WAVE, 2011). As well as a direct cause of injury, ill-health, and death, violence affects women's health indirectly too. Women suffer consequences to their sexual and reproductive health including mental illness, forced/unwanted pregnancies, unsafe abortions, higher risks of sexually transmitted infections and HIV (Russo \& Pirlott, 2006; Terry \& Hoare, 2007; UNFPA , \& WAVE, 2011).

As a result of gender discrimination and lower socio-economic status, women have fewer options and less resources at their disposal to avoid or escape abusive situations and to seek justice (UNFPA , \& WAVE, 2011). There are different forms of gender-based violence, such domestic violence, or intimate partner violence, which is not an isolated, individual event, but rather a pattern of behaviors used against a survivor. The pattern of violence consists of a variety of abusive acts, occurring in multiple times over the course of a relationship (Lundell et al., 2018; Russo \& Pirlott, 2006; UNFPA \& WAVE, 2011).

Governments, institutions and agencies frequently lack the ability to address genderbased violence fully because gendered power relations are deeply entrenched in cultures (Russo 
\& Pirlott, 2006; Terry \& Hoare, 2007). Furthermore, research states that individual-level interventions are less effective than those combined with community-level interventions in achieving lasting transformative change (Sommer et al., 2018). Interventions need to use multidimensional strategies that address systems that perpetuate gender-based violence (Sommer et al., 2018; Terry \& Hoare, 2007). Literature suggests that in order to end gender-based violence interventions must target the root of the problem, which is unequal power dynamics and harmful gender norms (Russo \& Pirlott, 2006; Sommer et al., 2018; Terry \& Hoare, 2007). However, these social interventions are difficult to implement, measure, and achieve transformative outcomes (Sommer et al., 2018).

Social work responses and interventions to gender-based violence frequently focus on individual or family treatment (Colarossi, 2005). Terms such as family violence or domestic abuse, centers the issue within the family unit, rather than understanding gender-based violence as a social problem (Colarossi, 2005). This ideology that exists within social work which primarily focuses on individual pathology and treatment does not incorporate social justice responses to the marginalization of people through gender-based violence (Colarossi, 2005). It is the responsibility of social workers to challenge the current practices to understand gender-based violence in the broader social context, adopting new terminology, policies and practices that critically address issues of western, colonial, patriarchal structures (Brownridge, 2003; Colarossi, 2005).

Within this research project, I have interviewed three survivors that self-identify as gender, sexuality and/or racial minorities. In viewing the issue of gender-based violence through a lens of intersectional transfeminism I included research literature specifically on racialized and LGBTQ survivors of gender-based violence to provide a representative research context for this 
paper. Research demonstrates that numerous components of a person's identity will impact the way they experience violence and experiences of gender-based violence differ according to the identities of both survivors and perpetrators (Calton, Cattaneo \& Gebhard, 2016; Crenshaw, 2003).

Gender-based violence is an issue that is not only experienced by cis-women, but sexual and gender minorities as well. In fact, research indicates that lesbian, gay, bisexual, transgender, and queer (LGBTQ) individuals are at higher risk of violence and victimization by others, and that transgender individuals may be at even higher risk than people that are cisgender (Calton, Cattaneo \& Gebhard, 2016; Charest, Kleinplatz \& Lund, 2016; Edwards, Littleton, Sylaska, Crossman \& Craig, 2016; Edwards, Sylaska, Barry, Moynihan, Banyard, Cohn, Walsh, Ward, 2015;Espelage, Merrin \& Hatchel, 2018; Langenderfer-Magruder, Whitfield, Walls, Kattari, \& Ramos, 2016; Status of Women Canada, 2017).

Calton, Cattaneo \& Gebhard (2016), discuss the importance of highlighting the unique stories of LGBTQ experiences of violence within relationships. LGBTQ intimate partner violence can include power and control tactics that are specific to minority sexual orientation or gender identity, such as threats of disclosure and the use of homophobia, heterosexism, or transphobia against a partner (Calton, Cattaneo \& Gebhard, 2016; Langenderfer-Magruder et al., 2016). Espelage, Merrin \& Hatchel (2018), discuss a particular study where 109 lesbian, gay and bisexual youth were asked to identify reasons for violence in their romantic relationships. It was reported violence could arise from internalized homophobia and the pressure to adopt socially prescribed gender roles (Calton, Cattaneo \& Gebhard, 2016; Espelage, Merrin \& Hatchel, 2018; Edwards et al., 2015). Furthermore, LGBTQ survivors are less likely to talk about their dating 
experiences, particularly if their gender or sexual identity is not known by others (Espelage, Merrin \& Hatchel, 2018).

Literature demonstrates there are significant differences between heterosexual and LGBTQ+ individuals in their sources of sexual health information. It was found that material presented in school and university courses are not as relevant for LGBTQ+ young adults. The results indicated heterosexual students felt more confident in their sexual health and practices than LGBTQ+ students (Calton, Cattaneo \& Gebhard, 2016; Charest, Kleinplatz \& Lund, 2016). Education and research on gender-based violence frequently focuses on heterosexual lived experiences, often excluding the LGBTQ+ experiences within analysis (Calton, Cattaneo \& Gebhard, 2016; Edwards et al., 2016; Langenderfer-Magruder et al., 2016). Although the literature is beginning to view LGBTQ experiences, it targets differences of sexuality rather than gender identities, reinforcing a gender binary (Calton, Cattaneo \& Gebhard, 2016; LangenderferMagruder et al., 2016). Overall, this creates a barrier within research and education to understand the complexities of what gender-based violence can look like in society.

Research demonstrates that gender-based violence is experienced differently based on intersections of people's identity such as race, gender, sexuality, ability and class (Crenshaw, 2003; Status of Women Canada, 2017). Specifically, there is unequal experiences of violence for racialized women in comparison to white women (Crenshaw, 2003; Status of Women Canada, 2017). Race and culture exist as contributing factors to silencing survivors, due to the impacts of colonialism and white supremacy (Crenshaw, 1993). Racialized women frequently experience feelings of reluctance in reaching out for support because of factors such as internalized racism, or fear of disclosure (Crenshaw, 1993; Sokoloff \& Dupont, 2005). 
Research highlights the experiences of violence for racialized women are frequently a result of intersecting patterns of discrimination through both racism and sexism (Sokoloff \& Dupont, 2005). Statistics Canada (2013), reported the rate of self-reported violence against Indigenous women was 2.5 times higher than non-Indigenous women, which was the case for partner violence as well as family, friends, acquaintances and strangers. The most serious form of violence against Indigenous women is homicide, and the issue of missing and murdered Indigenous women in Canada has been identified at both the national and international levels (Anderson, 2016; Statistics Canada, 2013).

Research demonstrates how intersections of a person's identity influence the way they experience gender-based violence. This Major Research Project contributes to the existing literature that views the issue of gender-based violence as intersectional, complex and experienced differently based on components of a person's identity. Through interviewing survivors with complex racial, gender, and sexual identities, the research findings in this paper discuss what makes their experiences unique while participating in drama. Overall, adding to the existing literature that seeks to understand the transformative experiences of drama and performance art. Moving forward with an intersectional, transfeminist, Anti-Oppressive Social Work framework of understanding gender-based violence, I review research literature on drama and performance art.

\section{Drama and performance art:}

Within this section I discuss the potential of drama and performance art for survivors of violence, and how it can contribute to Anti-Oppressive social work. I reviewed articles and studies that have viewed drama and performance techniques in a variety of settings, such as psychotherapy clinics, community theatre programs, universities, prison settings, shelters, and 
group counselling. Specifically, I explore the potential and differences of dramatherapy, psychodrama and theatre of the oppressed. For the purpose of this research project, I review literature that explores the use of drama and performance art techniques with people that have experienced gender-based violence. I accessed a variety of research databases such as social work, psychiatry, psychotherapy, dramatherapy, mental health practice, and education. I discovered there is limited data on this research topic focusing specifically on the experiences of survivors of gender-based violence. This is important to note in trying to gain an understanding into the unique experiences of survivors and the accessibility of drama and performance art for this population.

Drama and performance art utilize interactive techniques that can be used in a group or individually and can include: writing and learning scripts, role play, improvisational exercises, mime, spoken word, dance/movement, poetry and using props such as puppets or masks (Emunah, 1994). Research literature focusing on drama and performance art within therapeutic settings, such as counselling with individuals or groups, demonstrated positive impacts of drama and performance art techniques. Findings indicated drama provided a creative outlet where participants could process their experiences of violence, while strengthening the relationship with oneself and others (Carbonell \& Parteleno-Barehmi, 1999; Frisina, 2010; Jarman, 2014; Kirk, 2015; Mackenzie, 2013; Rousseau et al., 2007; Testoni et al., 2015). Additionally, common themes within the research findings revealed that when people participated in drama and performance art they experienced an increase in self-esteem, self-awareness, and connection to others (Dix, 2015; Frisina, 2010; Jarman, 2014; Kirk, 2015; Mackenzie, 2013; Oon, 2010; Orkibi et al., 2014; Rousseau et al., 2007). 
Literature viewing the unique experiences of drama techniques with survivors of violence highlights the potential of drama and performance art to challenge the cycle of violence (Dix, 2015; Jarman, 2014; Testoni et al., 2015). The findings of these qualitative and quantitative research studies suggest that drama holds the potential to provide a platform where survivors could both understand their experiences of violence, while positively transform the patterns of their own behavior (Dix, 2015; Jarman, 2014). The studies worked with young boys that were exposed to domestic violence. Drama techniques were used to challenge normative gender roles and norms of toxic masculinity (Dix, 2015; Jarman, 2014). The findings of these research studies speak to the potential of drama to not only positively impact the lives of individuals, but to also challenge a larger social problem. This literature demonstrates the capacity of drama and performance to contribute to Anti-Oppressive social work, because it is not only focusing on the individual experience, but working towards prevention of a social issue, such as gender-based violence (Bains \& Edwards, 2015; Wong \& Ying Yee, 2010).

In reviewing research literature regarding drama in therapeutic settings such as psychotherapy or clinical counselling, it is frequently referring to as either dramatherapy or psychodrama (Carbonell \& Parteleno-Barehmi, 1999; Cheung, Alzate, \& Nguyen, 2012; Dehnavi, Bajelan, Pardeh, Khodaviren, \& Dehnavi, 2016; Dix, 2015; Dogan, 2010; Frisina, 2010; Jarman, 2014; Kirk, 2015; Mackenzie, 2013; Moore, Andersen-Warren, \& Kirk, 2017; Oflaz, Meric, Yuksel, \& Ozcan, 2011; Oon, 2010; Orkibi, Bar, \& Eliakim, 2014; Rousseau, Benoit, Gauthier, Lacroix, Alain, Viger Rojas, \& Bourassa, 2007; Testoni, Armenti, Ronconi, Verdi, Wieser, Bucuta, \& Tarashoeva, 2015). Although drama therapy and psychodrama share common themes, there is one fundamental difference. Within psychodrama, the psyche is the aim 
and the drama is the means, whereas in drama therapy the drama itself is the aim and the psyche is the means of expressing the drama (Kedem-Tahar \& Felix-Kellermann, 1996).

A methodological gap existing within research literature viewing drama techniques specifically through dramatherapy or psychodrama is that it is frequently rooted in medical, psychological, evidence-based research. Within these research studies, the impacts of drama are frequently measured on the changes within the individual, with minimal link to the social problem that is creating the issue the individual is experiencing (Carbonell \& Parteleno-Barehmi, 1999; Cheung, Alzate, \& Nguyen, 2012; Dehnavi, Bajelan, Pardeh, Khodaviren, \& Dehnavi, 2016; Dix, 2015; Dogan, 2010; Frisina, 2010; Jarman, 2014; Kirk, 2015; Mackenzie, 2013; Moore, Andersen-Warren, \& Kirk, 2017; Oflaz, Meric, Yuksel, \& Ozcan, 2011; Oon, 2010; Orkibi, Bar, \& Eliakim, 2014; Rousseau, Benoit, Gauthier, Lacroix, Alain, Viger Rojas, \& Bourassa, 2007; Testoni, Armenti, Ronconi, Verdi, Wieser, Bucuta, \& Tarashoeva, 2015). Drama therapy has historical roots in both psychotherapy and theatre (Emunah, 1994). As a result, a large portion of the research found surrounding drama therapy derives from a psychological framework. Drama therapy within psychotherapy encompasses the use of dramatic practices to achieve psychotherapeutic goals (Grayer, 2005). Jarman (2014), conducted a study in England exploring drama therapy with a group of young boys that had lived experience of domestic violence within their family. The findings of this study discovered through utilizing drama techniques, the participants were able to reflect on their difficult experiences, while challenging their internalized problematic attitudes about domestic violence (Jarman, 2014). The study also highlighted the accessibility of drama to provide a space where participants of various developmental levels to explore difficult emotions and traumatic experiences. Overall, the study demonstrated the ability of drama to be inclusive of participants with complex identities (Jarman, 
2014). Overall, this showcased the potential of drama to facilitate individual healing, while simultaneously preventing a social problem.

Grayer (2005), examined long-term intensive psychotherapy with a female survivor of severe childhood abuse. Together they incorporated improvisational acting techniques to access repressed memories and understand the impacts of her trauma. Grayer (2005), discusses the ability of improvisational acting to protect survivors in moments that are emotionally overwhelming and its ability to be a catalyst to process their fear and pain. The article frequently highlights the client's sense of freedom while participating in improvisational acting, which allowed for creative solutions in her daily life outside of the therapeutic setting (Grayer, 2005).

Similarly, a research study in England explored drama-therapy with 15 female survivors of domestic violence. The short-term 12-week study was conducted to compare women who received individual dramatherapy with women who received individual support worker intervention (Kirk, 2015). The women selected for the drama therapy group were provided an approach using combined art movement and music therapies. The data was collected and evaluated through a clinical outcomes and routine evaluation system, which is used in the UK to assess "psychological distress". The results of this evaluation showed significant improvements in the reduction of mental distress for the group of women involved in drama therapy compared to the women who attended individual sessions (Kirk, 2015). The findings of this study display a valuable comparison between individual worker intervention and dramatherapy, which highlights the unique potential of drama techniques and positive impacts on survivors.

Hung (2010), explored drama therapy with women from Taiwan, previously referred to as "comfort women" during the second world war (p. 60). These women were used as sex slaves 
and left with serious life-long physical and psychological trauma. Hung (2010), discusses the use of drama therapy in the process of recovery from trauma, highlighting drama therapy and theatre representing a sacred place in many cultures used for therapeutic purposes. This research article demonstrates the significance of race, religion, and culture on the healing process for survivors of violence. Within traditional social work responses to gender-based violence, such as individual models of talk therapy, these often do not create space for these essential components of a survivor's identity.

Additionally, a residential drug and alcohol co-occurring disorder treatment facility in California, named "Project Pride", viewed the impact of drama therapy with incarcerated women. The program utilized various drama techniques, including sound and movement exercises, improvisational games, writing and performance (Leeder \& Wimmer, 2006). The results of this program described how drama encouraged playfulness and spontaneity, while building trust and teamwork among women. Additionally, the article highlighted how numerous survivors of violence on their paths to wellness find themselves in institutional settings such as shelters, treatment centers, or prisons and drama therapy was useful in exploring topics of domestic violence and healing past trauma (Leeder \& Wimmer, 2006). Project pride provided insight into how drama and performance techniques can allow for trust and relationship building within confined institutional settings such as a women's prison. Furthermore, it discussed how drama can be beneficial for survivors with complex identities and life experiences that frequently find themselves within these settings at different points in their lives.

\section{Theatre of the oppressed \& art as activism:}

As previously mentioned, the literature surrounding dramatherapy and psychodrama is frequently rooted in western, medical, psychology discourse, which focuses on individual 
experiences, rather than social change. This research project intends to contribute to AntiOppressive Social Work research by understanding the transformative process of drama and performance art and how it can be a vehicle to mobilize social change for survivors of genderbased violence. Therefore, it is imperative in my discussion of drama, performance and social change that I discuss literature focusing on art as activism and Theatre of the Oppressed.

Theatre of the Oppressed is an applied theatre form using improvisation and audience participation to explore social issues (Brigell, 2010; Giesler, 2017; Midha, 2010; Saeed, 2015; Shawyer, 2011; Stahl, 2018). Augusto Boal, theatre director and activist created Theatre of the Oppressed in Brazil and Peru in the 1960s. He rejected the idea that theatre could only be enjoyed by the upper class and started working with oppressed communities for the purpose of liberation and transformation (Brigell, 2010; Giesler, 2017; Midha, 2010; Saeed, 2015; Shawyer, 2011; Stahl, 2018). Boal believed that individual problems originate from societal oppression and that theatre could be used to address and connect all of these levels (Brigell, 2010; Midha, 2010). Boal noted that Theatre of the Oppressed is a rehearsal of revolution and a chance to explore options of action (Shawyer, 2011). The use of these theatre techniques requires strong facilitation skills and the flexibility to improvise based on the audience (Midha, 2010). Furthermore, these techniques have skills applicable to the fields of development, social work, education, politics, and the fine arts (Shawyer, 2011). Theatre of the Oppressed deals with specific problems such as sexual harassment and gender-based violence, and functions to propose action where the people that are most impacted by these issues are the ones who find ways to resolve them (Midha, 2010). 
The process of Theatre of the Oppressed changes people in the audience from spectators, which are passive beings, into actors or transformers of action to try out solutions. This action holds the potential to demonstrates societal divisions between the dominant and marginalized (Brigell, 2010; Giesler, 2017; Midha, 2010; Saeed, 2015; Shawyer, 2011; Stahl, 2018). There are four stages within Boal's Theatre of the Oppressed, which are: knowing the body, making the body expressive, theatre as language, and theatre as discourse (Giesler, 2017). In the first stage Boal strived for people to understand the human body as a vessel and vehicle out of oppression. When participants understand their own bodies as containers of oppression they can unlearn patterns, moving towards empathetic awareness. In the second stage participants learn how one's body can be just as expressive as words. In the third stage the participants, or spectators, are invited to become "spect-actors", meaning participants move into action and to act on their awareness to deconstruct and reconstruct the scenario. In the fourth stage of theatre as discourse actors choose a public setting and perform a script where bystanders can be introduced into the scene (Giesler, 2017). This can have the ability to raise awareness in a variety of spaces. For social work this is beneficial for people that search for simple answers, such as rooting an issue in a person, rather than understanding the complex society. The act of empowering, being an ally, or a catalyst for someone who is deciding to make a new choice (Giesler, 2017).

Shawyer (2011), discusses the use of Theatre of the Oppressed exercises and techniques with theatre students, who tracked their course progress through questionnaires and reflections. Class members described an inclusive nature, which encouraged both the oppressed and oppressor to work together to end inequalities (Shawyer, 2011). In one exercise, student volunteers role played a scene about sexism in the local bar. The class suggested options meant to change the inequalities in the scene. While some recommendations were briefly successful, the class was 
unable to solve the overall systematic class and gender oppression (Shawyer, 2011). However, although students felt frustrated by gender inequalities they experience daily, they recognized the activist potential within Theatre of the Oppressed (Shawyer, 2011).

Similarly, Giesler (2017), explains how Boal's work has the ability to establish sustainable link between theatre and social work practice to radicalize social work pedagogy. The article explains how Boal's exercises can be utilized within social work education to enhance student's awareness of self and others. Furthermore, drama and performance techniques allow for social work students to critically understand concepts such as empowerment, empathy and social change (Giesler, 2017). This article provides insight into how theatre can be utilized within classrooms to promote Anti-Oppressive social work by encouraging students to critically understand their social positioning within the larger social context. Overall, this creates awareness for social workers to identify how they may contribute to oppression and how to modify their behavior to facilitate social change.

In connecting Theatre of the Oppressed techniques to the issue of gender-based violence, Brigell (2010), discusses how theatre can be utilized for prevention of gender-based violence through exploring the limitations of the current constructions of masculinity. The article highlights a 12-week intervention with high school students, partnering with the local Rape Crisis Center. The program used drama and performance techniques such as role play to challenge gender definitions and roles, healthy relationships, sexual harassment, dating violence, and sexual assault. Researchers discovered drama allowed for participants to understand the impacts of their internalized assumptions and beliefs to social problems and move towards improving their knowledge and attitudes (Brigell, 2010). This article provides valuable insight 
into how drama and performance can be a vehicle where people can unpack their assumed gender roles to understand how they contribute violence.

Nadeau \& Sajani (2006), discuss the significance of race, religion and culture in the conversation of gender-based violence in their exploration of a theatre project in Montreal. The article highlighted how racialized immigrant women feared speaking out about violence, because it is frequently attributed to their culture within the colonial, racist, political structures that exist within the Canadian context (Nadeau \& Sajani, 2006). The project created a theatre piece and developed a training program for racialized immigrant women, aiming to understand how they face violence every day in and outside of their homes. The training explored approaches in drama, dance, and movement therapy to contribute to the repairs of violence in everyday life (Nadeau \& Sajani, 2006).

The process of this project demonstrated how drama can act as a platform for women with complex identities to discuss their experiences of intimate partner violence, as well as structural violence of both racism and sexism within Canadian society (Nadeau \& Sajani, 2006). Overall, the program found the process of drama and performance led to solidarity among women and determination to mobilize collectively for social change (Nadeau \& Sajani, 2006). The results of this project speak to the potential of drama to contribute to Anti-Oppressive social work through acting as a unique platform where women can creatively connect to themselves, others, and advocate for social change (Bains \& Edwards, 2015; Wong \& Ying Yee, 2010).

Similar to Nadeau \& Sajani (2006), Saeed (2015) highlights the significance of race, culture, religion on gender-based violence, and how drama techniques can be used for collaboration to instill both short-term and long-term social changes. The article discussed the use of Augusto Boal's Theatre of the Oppressed with women in Afghanistan. It highlights how Afghan women 
are frequently portrayed throughout the mainstream media as voiceless and weak, which does little to represent the complex experiences of women that are resisting oppression on a daily basis (Saeed, 2015). Theatre of the Oppressed has been used in initiatives within Afghanistan in a number of projects, one specifically focusing on women and gender issues, using theatre techniques to challenge social norms and question the status quo, having their voices translated into political agency (Saeed, 2015). The project was implemented in five provinces, engaging 5,000 women through participatory theatre. The article highlighted how this project allowed for every day women to move beyond their individual stories and connect their experiences to larger society (Saeed, 2015). Women experienced feelings of empowerment, enthusiasm, confidence and energy to find their voice to change their lives. The final stage of the project compiled a report with legislative recommendations to respond to gender-based violence and submitted this to the Gender and Human Rights Committee (Saeed, 2015). This article demonstrates how drama can connect, empower and mobilize people towards social change.

Drama and performance art can be accessed in various settings for a wide range of goals, with diverse groups of people. However, common themes within all articles in discussing the impact of drama was its ability to be a creative outlet where participants could understand their own experiences, gain confidence, power, empathy and self-awareness, while connecting to others (Brigell, 2010; Carbonell \& Parteleno-Barehmi, 1999; Frisina, 2010; Giesler, 2017; Jarman, 2014; Kirk, 2015; Mackenzie, 2013; Nadeau \& Sajani, 2006; Rousseau et al., 2007; Saeed, 2015; Stahl, 2018; Testoni et al., 2015). Furthermore, drama can act as a platform where participants can build skills and language that allows them to contribute towards social change (Brigell, 2010; Giesler, 2017; Midha, 2010; Saeed, 2015; Shawyer, 2011; Stahl, 2018). 
The reviewed research literature on drama therapy, psychodrama, and Theatre of The Oppressed demonstrate the potential of drama to contribute to Anti-Oppressive Social Work. Research findings indicate dramatherapy and psychodrama provided a creative outlet where participants could understand their experiences of violence, gain power, self-esteem, and empathy, while strengthening the relationship with oneself and others (Carbonell \& PartelenoBarehmi, 1999; Dix, 2015; Frisina, 2010; Jarman, 2014; Kirk, 2015; Mackenzie, 2013; Rousseau et al., 2007; Testoni et al., 2015). Theatre of The Oppressed explored how drama techniques, such as role play, can be used for collaboration to instill both short-term and long-term social changes (Saeed, 2015). Theatre of the Oppressed encouraged participants to challenge genderbased violence though understanding gender definitions and roles, healthy relationships, sexual harassment, dating violence, and sexual assault through the use of drama techniques (Brigell, 2010). This allowed participants in drama to understand the impacts of their own beliefs and assumptions about a social problem, such as gender-based violence, to move towards improving their knowledge to create social change (Brigell, 2010; Giesler, 2017; Midha, 2010; Saeed, 2015; Shawyer, 2011; Stahl, 2018). The reviewed literature demonstrates the capacity of drama and performance art to contribute to Anti-Oppressive Social Work Practice, because it does not solely focus on the individual and has the creative ability to challenge social issues, such as gender-based violence (Bains \& Edwards, 2015; Wong \& Ying Yee, 2010).

Throughout the reviewed literature there is a number of identified gaps, which this research project contributes to. A gap discovered in the literature is that few articles specifically focus on in-depth experiences of the unique process of drama and performance art with survivors of gender-based violence. The research presented on both dramatherapy and psychodrama frequently view the experiences of participants from an individualistic, western perspective, 
which influences how drama is understood (Carbonell \& Parteleno-Barehmi, 1999; Cheung, Alzate, \& Nguyen, 2012; Dehnavi, Bajelan, Pardeh, Khodaviren, \& Dehnavi, 2016; Dix, 2015; Dogan, 2010; Frisina, 2010; Jarman, 2014; Kirk, 2015; Mackenzie, 2013; Moore, AndersenWarren, \& Kirk, 2017; Oflaz, Meric, Yuksel, \& Ozcan, 2011; Oon, 2010; Orkibi, Bar, \& Eliakim, 2014; Rousseau, Benoit, Gauthier, Lacroix, Alain, Viger Rojas, \& Bourassa, 2007; Testoni, Armenti, Ronconi, Verdi, Wieser, Bucuta, \& Tarashoeva, 2015). The reviewed research literature focusing on Theatre of The Oppressed frequently views the experiences of group participation in drama techniques, which does not provide rich details of the processes of drama (Brigell, 2010; Giesler, 2017; Midha, 2010; Saeed, 2015; Shawyer, 2011; Stahl, 2018).

Another gap identified within the literature is that few articles highlight the experiences of gender minorities, such as members of the LGBTQ community, when unpacking the issue of gender-based violence. Through excluding LGBTQ experiences in framing the social issue of gender-based violence this functions to exclude many survivors with unique identities (Calton, Cattaneo \& Gebhard, 2016; Edwards et al., 2016; Langenderfer-Magruder et al., 2016). This research project expands the understanding of gender-based violence using an Anti-Oppressive, intersectional, transfeminist framework. Each participant interviewed in this paper identifies as a member of the LGBTQ community and connects their gender and/or sexual expression to their participation in drama. The findings within this research paper discuss how intersections of a survivor's identity, including race, gender and sexuality, connect to their experiences participating in drama and performance art.

This qualitative research project uses in-person interviews with three survivors to gather details about their experiences participating in drama and performance art. Although the sample size in this research paper is small, it allows for the ability to gather rich data focusing on the 
transformative experience of drama and performance art with survivors of gender-based violence. This research paper moves beyond viewing drama in a therapeutic setting to understand how drama operates in a variety of settings to gather details about the inherently transformative potential of drama and performance art. The findings presented within this research paper will contribute to gaining a deeper understanding of what makes the experience of drama unique for survivors of gender-based violence. 


\section{CHAPTER 4. METHODOLOGY}

This research study uses a qualitative research design to gain a deep understanding of survivors of gender-based violence lived experiences of drama and performance art. I am guided by interpretive phenomenology to provide the framework for the research design in this project. An interpretive approach to research provides a theoretical basis for gaining an empathetic understanding of how survivors of gender-based violence give meaning to their interactions and experiences of drama. Using an interpretive approach, this research incorporates the narratives of participants in the final report writing through the use of direct quotes to ground the research findings in the lived experiences of survivors.

\section{Interpretive phenomenological analysis:}

This small qualitative research study incorporates a phenomenological research design to understand the transformative experience of drama and performance art with survivors of gender-based violence. Interpretive phenomenology is an approach to qualitative research that aims to interpret a common meaning that individuals give to their lived experience of a phenomenon (Preston \& Redgrift, 2017). Interpretive phenomenology will be used in this research to understand how survivors of gender-based violence interpret their experiences and participation in drama and performance art. I view survivor's interpretations of their experiences participating in drama to understand the potential of drama when accessed by survivors. It is important to note that the goal of this research is not to produce findings that can be generalized to the general population of survivors of gender-based violence. Rather the aim of this research project is to gather rich information from the stories of three survivor's experiences participating in drama and performance art. 
Through using an Anti-Oppressive, intersectional, transfeminist lens with an interpretive approach, I gain a critical understanding of this phenomenon. Given that I am interpreting the meaning participants give to their experience, I am transparent of my rationale for including quotes and linking themes in order for readers to understand my positionality in relation to the data collected. Preston and Redgrift (2017), describe phenomenology as a form of AntiOppressive social work research. Phenomenology aims to analyze the lived experience of people within a distinct context and is focused on a person's experience with a phenomenon through exploring the essence of their experience (Preston \& Redgrift, 2017). Interpretive phenomenology assumes that people are actively engaging and interpreting events throughout their lives (Creswell \& Poth, 2018).

A goal within interpretive phenomenological research is to identify critical components of an experience that make them unique to others, while emphasizing the history and context of an individual's experience (Pietkiewicz \& Smith, 2012; Preston \& Redgrift, 2017). In this research context, my intent is to explore what makes drama and performance art unique to survivors of gender-based violence based on their interpretations of their experiences. An interpretive approach to this research will complement my theoretical framework, as it assumes that a person's reality is always impacted by social, cultural, and political factors (Preston \& Redgrift, 2017). In understanding that Anti-Oppressive social work practice is focused on challenging systemic injustice, interpretive phenomenology offers an opportunity to highlight systemic oppression, while contextualizing it within an individual's experience (Preston \& Redgrift, 2017).

Interpretive phenomenology includes the values of the researcher because this research framework contends that human beings cannot suspend their epistemology (Creswell \& Poth, 
2018). This aligns with Anti-Oppressive practice as it allows for the influence of the researcher to be more transparent (Pietkiewicz \& Smith, 2012; Preston \& Redgrift, 2017). This is a valuable component of interpretive phenomenology, as I am motivated in my research as a survivor of gender-based violence who has participated in drama. My lived experience of privilege, oppression and resistance will impact every step of the research process. Therefore, it is impossible for me to maintain an objective position throughout this research. I am transparent in my own assumptions of drama, while understanding participants experiences of this phenomenon through an Anti-Oppressive, intersectional, transfeminist lens.

Interpretive phenomenology asserts a researcher's values are interwoven throughout the research process. The researcher acts as a co-creator in developing a narrative with participants (Creswell \& Poth, 2018). Therefore, the analytical focus is on the shared meaning between participants and the researcher (Preston \& Redgrift, 2017). This approach aligns with AntiOppressive practice as it works towards dispelling a power imbalance that frequently exists between researcher and participants (Bains \& Edwards, 2015; Preston \& Redgrift, 2017; Wong \& Ying Yee, 2010). My goal in utilizing this methodology is to create space where participants unique interpretations of a phenomenon can connect and enhance one another. I critically reflect on my subject positioning and power throughout the research process to understand how this influences the way I view and analyze data (Preston \& Redgrift, 2017).

\section{Subject positioning:}

In understanding my personal experience and identity as a survivor of gender-based violence, drama and performance art provided a creative space for me to process personal challenges beyond traditional methods of communication. Drama became a consistent 
community where I could give and receive support through creative exploration. I believe there is potential strength in my identity because I am a member of the community that I am interviewing (Taylor, 2011). I understand the importance of conducting Anti-Oppressive research that is committed to inspiring social change (George, 2017). I am critically aware that my assumptions of drama are positive and transformative because that was my own experience.

Although I am a member of the community that I am researching, that does not mean that I am faultless in my exploration of this research, as insider views will be always be multiple and debatable (Taylor, 2011). My own positive experience of drama impacts my interpretations of other survivor's experiences. As a cis-white able-bodied woman, I understand that many women carry stories of violence and experiences of drama that are vastly different than my own (Baffoe et al., 2014). I am transparent of my interpretation throughout each step of the data collection process including transcription, coding and interpretive comments. I view participants experiences of drama through a critical theoretical framework of intersectional, transfeminist Anti-Oppressive Social Work Practice to link participants individual experiences to the larger social context. Therefore, maintaining a critical framework that allows for representation of intersecting identities. I intend to uncover my assumptions and biases through including my interpretive comments within the discussion and analysis section of the paper, which explain in more detail my interpretation of participants experiences of drama. Each of the identified themes are grounded in direct quotes from participants to ensure research findings are centered in participants understanding of their experiences. 


\section{The study:}

I am using a qualitative research design, conducting one-hour in-depth interviews with three participants who have both lived experience of gender-based violence and drama and performance art. During each interview I did periodic check-ins to ensure the participants were comfortable and not feeling anxious or upset. Within the interviews, a natural dialogue was facilitated between myself and participants, which allowed for participants to guide the discussion of their stories. However, the interview guide was accessed throughout each interview periodically to ensure specific questions were answered. All participants answered questions without asking for a break or to skip. Out of the three participants, one became briefly emotional when discussing her gender identity and the violence she faced, but she completed the interview.

In understanding that gender-based violence is experienced differently based on intersections of a person's identity, I began each interview by gathering participants demographic information regarding their identity in terms of their race, sexuality, gender, socioeconomic status, and (dis)ability. Following the demographic questions, I moved into the qualitative portion of the interview, where participants were given space to share their stories of participating in drama. An interview guide consisting of roughly twenty questions, with prompts, was accessed throughout each interview to guide myself and the participants.

The qualitative interview questions consist of: How would you explain gender-based violence? At what time(s) in your life did you experience gender-based violence? Did you access services/support following your experience(s) of violence? What impact did accessing these services/support have on your life? What do you think are the biggest barriers in accessing support following an incident of violence? How and when did you become involved in drama and performance art? Can you describe the type/kind/method of drama and performance art you 
participated in? How would you describe the process of participating in drama and performance art? Following participation in drama, did you recognize any changes in other areas of your life? What are the biggest barriers for accessing and participating in drama? If you had the opportunity, what would you tell a survivor of violence who was thinking of participating in drama? How do you think drama can or cannot contribute to social change; particularly in relation to gender-based violence?

It is important to note that the goal of this research project is not to gain details of participants experiences of gender-based violence. Rather, I want to understand how the experience of participating in drama is unique for survivors. Through gaining answers to these interview questions, I will link how drama has contributed and impacted the lives of survivors. The interviews were audio recorded for the purpose of transcription and analysis. Following each interview, a list of resources with agencies offering support services was provided.

\section{Recruitment:}

Participants for this research project were mainly recruited through word of mouth and snowball sampling. A recruitment flyer detailing information about participating in this research study was posted in a private Facebook group on titled "Bunz theatre home zone", which is a social media platform for people in the theatre community. I used my personal Facebook page to post in this private group due to the fact that certain groups, such as Bunz Theatre Home Zone, are closed and one needs to be an approved member to receive access. To ensure no one felt obligated to participate in the study, I posted the recruitment flyer and disabled comments while highlighting participation is completely voluntary. I specifically requested interested participants to contact me through my Ryerson email if they have questions regarding the research study to respect privacy. 
Recruitment flyers were also emailed to support services, community agencies and local theatres. These included: Buddies in Bad Times, Tarragon, Why Not Theatre and The Canadian Stage, The Toronto Rape Crisis Centre/Multicultural Women Against Rape (TRCC/MWAR), Nellies Shelter, and The 519. Out of these organizations Buddies in Bad Times and The Canadian Stage responded and stated they would pass on the recruitment flyer to interested participants. Participants voluntarily contacted this researcher through email and I sent them a consent form with more information regarding the study. Email was used primarily for communication between myself and participants. Once participants read and understood the consent form a date and location of the interview was scheduled.

\section{Sampling and criteria for selection:}

I expanded my research sample to achieve a diverse sample of participants in their identities as both survivors of gender-based violence and participants in drama and performance art. I did not specifically recruit participants that intentionally accessed drama and performance art to overcome violence. Interested participants were only required to identify as survivors of genderbased violence who had participated in drama and performance at some point in their lives. I did not specify the setting or time when they participated in drama.

Therefore, I did not specifically recruit participants from therapeutic settings. It is my intention in this research paper to understand how drama is therapeutic for survivors outside of these specific settings, expanding this to understanding how drama is transformative within the community. I did this to understand how drama can be a therapeutic tool, rather than a specific therapeutic modality, viewing how people are accessing this in their own lives to move forward 
from gender-based violence. This was done intentionally to understand the organic experience of drama within and outside of these structured settings.

\section{Data collection:}

This Major Research Paper is intended to be of minimal risk to participants. The goal of this research is to explore the following question: What is the unique experience of drama and performance art when accessed by survivors of gender-based violence? As required by the Ryerson University REB, which approved this research project, participants were informed of the nature of the study prior to the interview. Participants were informed of the steps being taken to ensure confidentiality, such as omitting all personal information and personal identifiers discussed in the interview. Participants were provided a copy of the consent form prior to agreeing to participate in the interview to ensure they understood participation and have an opportunity to ask any questions about the study. The consent form was reviewed again in person prior to conducting the interview. After explaining the interview process, participants signed the consent form.

All three participants consented to the audio recording of their interviews for the purpose of transcribing the data and coding. At any given time of the interview, participants were told they could withdraw from the research study, and information that was provided would be destroyed and not used in the final results of the research paper. Prior to the interview, participants were made aware of the emotional risk in participating in the interview, as they may be sharing personal stories and experiences about drama and gender-based violence, which could cause feelings of discomfort. Due to this potential risk, participants were informed prior to conducting the interview that they may temporarily or permanently skip a question or withdraw from the study completely without consequences. 
In order to obtain rich detailed data, roughly one-hour in-depth interviews were separately conducted with each of the three participants. The location of each interview was mutually agreed upon by the participant and researcher and booked in a private and confidential space. The interview is guided by semi-structured, qualitative interview questions approved by the Ryerson University REB. I collected demographic information to gain an understanding of how participants self-identified their race, sexuality, gender, (dis) ability, and socio-economic status. Participants primarily guided the discussion, reflecting on their experiences as survivors of gender-based violence and the process of participating in drama. The interview guide was used to ensure all elements of the research question were answered to allow for in-depth analysis. I collected email addresses during the recruitment process in order to facilitate interview times and ensure participant received the consent form to understand the nature of their participation. Information was securely stored electronically with password protection and will be destroyed following submission of this research.

\section{Coding:}

In using an interpretive phenomenological approach to this research study, the process of coding the data included completely immersing myself in the data to understand participants experiences of drama (Pietkiewicz, \& Smith, 2012). After the interviews were conducted, follow-up work for each interview was completed. Audio recordings were listened to numerous times to recall the setting and atmosphere of each interview. Each time I listened to the audio recording I would journal my own thoughts and interpretations. These notes included reflections about the interview experience highlighting what was discussed, repeated or distinct phrases, emotional responses and participants answers of potential significance (Pietkiewicz, \& Smith, 2012). 
The audio recordings of each interview were written into transcripts and coded with my own interpretive comments. Transcribed interviews were read numerous times in order to identify common and emerging themes after coding was completed. Transcripts were reviewed for emergent themes based on identical or similar content among participant narratives and placed into categories. These themes are categorized into headings and described with extracts from the interview(s), using participants own words to highlight themes (Pietkiewicz, \& Smith, 2012). The final analysis of the findings includes both participants reflection of their experience and my interpretive commentary. Analysis of the research findings focuses on each distinct theme as its own topic followed by an examination of possible relationships between themes and how they may influence one another. Additional information is discussed in more detail in the findings chapter.

\section{Profile of participants:}

In this section I will introduce the participants interviewed for this research study. The participants in this research were asked to disclose their age, as they are required to be the age of 18 or older to participate in the study due to the topic of gender-based violence. This research project focuses on the narratives of survivors of gender-based violence. As discussed in the literature review, gender-based violence is not only experienced by cis-women, but people who identify outside of this gender category. Therefore, participants were required to self-identify as

female, trans, gender queer or gender non-conforming and have lived experience of gender-based violence. Participants in this study were also required to have experience participating in drama and performance art at some point in their lives. Research questions seek to explore and understand survivors experience of drama and performance art in and how this creative process 
impacts, or does not impact, their lives in relation to the gender-based violence they have experienced.

I use pseudonyms for each of the three participants for confidentiality purposes. These participants will go by the pseudonyms of Amy, Devon and Sheela. Participants ages ranged from 20 to 35 . To gain an understanding of participants identity, I began by asking demographic questions regarding how each person identifies their gender, sexuality, race, ability and socioeconomic status. All participants used she/her pronouns, however Devon self-identified as both gender fluid and gender queer continuously throughout the interview.

The first person interviewed was Amy, who self-identified as a Caucasian, lesbian, transwoman. Although she identified as able-bodied, she discussed a history of struggling with mental illness and frequently experiences depression in her daily life. Amy identifies as lower middleclass. Secondly, Devon self-identified as mixed race; Indian, German and Hungarian. Devon uses female pronouns, however she self-identified as gender-fluid and gender-queer throughout the course of the interview. Devon identified her sexuality as queer/bi-sexual/pan-sexual. She explained that she is mentally ill and has been diagnosed with epilepsy, which she is on medication for. Devon identifies lower-class, and explained she is currently living under the poverty line. Lastly, Sheela self-identified as a Caucasian, bi-sexual cis-female. She explained struggling with mental illness and identifies as lower-middle class. 


\section{CHAPTER 5. RESEARCH FINDINGS}

In this section, I will present the emerging themes that arose through the process of coding transcripts from the in-person interviews with all three participants. Following the presentation of the themes, I will move into an analysis and in-depth discussion of these findings. There were many themes that emerged through the interviews, therefore I have organized the findings into four main themes with sub-themes. The following themes and sub-themes are: Gender-based violence: power imbalance, gender norms and expectations; Barriers in support seeking: invalidation, fear, and shame; Experience of drama and performance art: representation, empowerment, coping skills, and connection to self and others; and finally, Drama and social change.

\section{Gender-based violence: power imbalance:}

A major component of this research project is understanding what makes the experience of drama and performance art unique for survivors of gender-based violence. Therefore, interviews with participants began with exploring their conceptualization of gender-based violence based. Due to the originality in each participant's identity and lived experience every person answered from a unique perspective. However, two major sub-themes emerged throughout each participants reflection of gender-based violence. The first sub-theme that emerged was power imbalance. Each participant in their own words understood gender-based violence as an issue of imbalance of power, such as power over someone and loss of power for specific people within society. Overall, communicating certain people, mainly cis-men are given more power in society, fueling the issue of gender-based violence. The following quotes are highlighted directly from participants responses discussing how they view gender-based violence as an issue of power imbalance within their lives; 
I think gender-based violence is... across the board in a number of different ways, like obviously it can be physical, mental, emotional... and then even within each of those branches it can have its own sub-branches as to how it plays out, but obviously its power and control a lot of the time. It can also just be and come from different places, whether it is an exercise of a feeling of superiority, whether it's an exercise of hatred, that's my objective understanding (Amy).

Gender-based violence ...is...I mean it's a power situation I think. In terms of the way the world has been set up for a long time is that men have been in power, particularly cis straight white men have been in power since ...forever. No matter where you go, there is a sense of entitlement that comes from men specifically. They don't even realize they have it. They are so used to the world operating this way, I do believe people contribute to gender-based violence in ways they don't even know they're doing because it's just what they have learned (Devon).

Gender-based violence in Canada... we have the full spectrum of it. Right from you know...going to talk about buying a car and having somebody ignore you....well that's not really violence... but its stemming from the same seed, like somebody is dehumanizing you and thinking "oh you don't know anything" ...but it comes from the same seed...thinking that women, or women-identified people are less than (Sheela).

Every participant identified feeling as though it was difficult to summarize all of the factors that contribute to a very complex issue such as gender-based violence. However, each participant highlighted the issue of an unequal power dynamic that is interwoven within the fabric of Canadian society. This unequal power dynamic fuels issues such as gender-based violence within society and functions to marginalize people based on their gender expression or identity.

\section{Gender-based violence: gender norms/expectations:}

A second sub-theme that emerged in the discussion of gender-based violence was the link to societal gender norms and expectations. To gain an understanding of the link between participants experience of violence and their participation in drama and performance art they were asked at what time in their lives they experienced violence. Given each participant's unique identity, they had experienced different forms of violence in different social spaces throughout their lives based on intersections of their identity. However, within each participants story, every 
person connected their gender identity and expression to the violence they experienced.

Participants shared how social norms and expectations regarding gender led to different forms of violence. Firstly, Amy recalled on her experiences of violence as a trans woman being raised and socialized as a male in society. She describes how her gender expression was met with different responses of violence as she grew older;

It was confusing because early on in my life I was allowed to be fully expressive. Life was absolutely extravagant and then it reached a point where all of a sudden it was like "no you can't do that, boys don't do that". Ever since then I was kind of invalidated in how I wanted to express myself, and it really started affecting my perceptions of reality. To this day I still have huge anxiety triggers around feeling like I am losing grasp on reality, because for me to know myself so intrinsically and have that to be invalidated just to... you know like I had to play the part...like live life how they all saw me to be, and...I don't know that screwed me up big time.

Amy describes feeling as though her gender identity was invalid, which impacted her mental health and perception of reality. Similar to Amy's experience in striving to express her femininity, these social gender norms impacted Devon as well. Devon reflected on forms of violence she experienced and discussed the fluidity of her gender expression. She explained feeling confined to certain spaces because of her physically female body. Devon expands on this, stating throughout her life she has always operated in spaces that were taken up by men and was expected to act differently based on how others perceived her gender;

I feel very androgynous in the soul area.... like I don't walk around and talk to people and think about how they perceive me, and I've run into problems with that. I've had boyfriends that have been like "do you realize how you were talking to them? You totally led them on".

The reaction Devon received from her boyfriend speaks to gender expectations that are based on a binary between males and females. These expectations create social norms that males and females are required to follow in order to fit into the structures of society. If one does not fit into this binary there is frequently negative consequences, which can include violence. Sheela 
describes similar experiences which communicate that she is "less than" based on her identity as a cis-female. Sheela explained various incidences where people would demand her time or attention and if she didn't give this to them it would escalate to verbal or even physical violence. She explained how the result of violence is because she is not giving them what they believe they are entitled to. Sheela described the dehumanizing experiences she has faced as a cis-woman and the expectations that surround her body with multiple people;

I've experienced that.....daily....where um...they want my time or they want my attention... and when you don't give them what they want, that's when I think most of the violence can be verbal, going from "hey I really wanna talk to you I think you're really cute" to "oh you're not giving me attention fuck you, you fat fucking bitch". I have been groped, I have been assaulted. That's happened with strangers, that's happened with partners. I mean...I'm a white woman. I have a privilege there, where...if I called the police, maybe they would help me. I have a higher chance of getting help than say an Indigenous woman...I mean look what's happening there. I think were wrong to think that Canada is a very progressive safe place.

Sheela connects the violence she has experienced to intersections of her identity, highlighting the privilege she carries as a cis-white woman in Canada. Although she is vulnerable to violence because of her gender identity, she holds privilege in her racial status as a white woman. Similar to Devon's experience, she describes numerous times of people blaming her sexual and gender presentation for her experiences of violence. Sheela recalls frequent comments such as, "oh well you know you are a stripper" and "I'm not saying it's your fault sweetheart, but if you don't want things like that to happen to you..." These comments are additional forms of violence, communicating that if a survivor only presented their gender and sexuality appropriately, they could have avoided experiencing gender-based violence. Devon further explains the issue of gender-based violence through a lens of intersectionality. She described the vulnerability people experience when they face multiple oppressions, specifically highlighting race and mental health; 
I find that people who are unwell, that are mentally ill, specifically women, specifically women of colour, experience more gender-based violence than other people because they just have more vulnerabilities...less power you know? I have taken up different spaces based on where I am. When I'm with white girls, I'm the not white girl, but when I'm with people of colour, I'm the white girl. It's a very weird thing. Guys have not dated me because I'm not white. I mean it was very hurtful. You know I spent most of my teenage years absolutely hating how I look because of it. It was very hurtful for a very long time.

Devon describes the exclusion she faced in many spaces as a bi-racial woman within society. She highlights the ability to experience both oppression and privilege depending on the space she occupies. Devon discussed how experiences of racism impacted her self-esteem, worth and her ability to create relationships.

Amy discussed growing up as a gender-minority, and that from a young age she would naturally express her gender identity but was always told it was wrong based on the physical body she was born into. These experiences became increasingly violent as Amy moved through educational institutions. Amy explained resisting her assigned male gender throughout her life and how this made her vulnerable to experiences of violence both within and outside the home. As Amy moved through educational institutions, she experienced frequent emotional, mental and physical violence from both her teachers and peers in the education system. She describes an early experience within the classroom;

I look back and so much of me was wanting to find an excuse to explore makeup and explore femininity in an accepted way for men, and as I was doing that I started getting beat up, I started getting a lot of name calling or whatever...I became suicidal [...] It got to a point in grade seven, kids pulled a chair out from under me, they beat me with the chair and threw my desk at me. I just remember standing there...feeling humiliated and obviously assaulted and just remembering the teacher didn't even say anything.

The different forms violence directed toward Amy led her to wanting to end her own life at a very young age. She recalled feeling completely humiliated, invalidated by both her peers and teacher who was required to care for all students. Amy continued to face discrimination 
based on her gender identity and expression as she came out publicly as a trans-woman. She discussed moving to Toronto after she came out because she knew it was important to be in a larger city, rather than the small town she grew up in. Despite moving to a city where there is more visibility for the LGBTQ community, she continued to experience violence;

One year ago, the May after moving to Toronto, some guy on the street car just kind of came right up and was like "what's going on with you? Like are you a boy or a girl? Like you don't need to throw this in our face" And I wasn't saying anything I was just listening to my friend and... you know we tried to politely back out of like conversation with him before it escalated and the TTC officers got involved and this guy got very aggressive and the cops were called.

Amy's story provides an example that demonstrates safety is dependent on a person's identity. These experiences of violence are described as invalidating, dehumanizing and humiliating from all participants. Every person identified carrying feelings of guilt and shame moving forward from violence. Sheela further describes difficulty navigating the social expectation of finding a male partner, as a bi-sexual woman, and the violence she experienced in her relationship with cis-men;

You are indoctrinated with this idea that having a boyfriend is an achievement, so getting one and keeping one is very central to how people see me as a successful, attractive, women. I think also interwoven in there is how downplayed women's own sexuality is....and how the game is that men want it and women's jobs is to say no. I've always been a very sexual person and that really fucked with me, because I would get into these relationships with men, and my sex drive would be higher, and they would resent me for that... and emotionally just tear me apart. I was emasculating them in ways and that would sometimes lead to ignoring, rejecting, or escalate to you know physical violence...

Sheela's story highlights sexuality and gender expectations that exist both outside and within intimate relationships. She describes the emotional violence that she faced because she was not able to meet these expectations. Similarly, Devon explained how men feel entitled to her body, despite her fluid gender identity. She reflected on a recent experience of sexual violence 
with a close friend and described challenges she faces with her mental health and how this made her vulnerable to violence;

I've been best friends with him for three years, we've traveled to different countries, we've slept in cars together. We were having a sleepover, I was feeling severely depressed, I called him, and he was the safest person I felt like I could go to. All I could do was get myself to his house, and he sexually assaulted me. The first thing that someone said to me was "why were you having a sleepover with a dude?"

Despite Devon feeling safe with a person she considered a friend and knew very well, she was sexually assaulted, and people questioned her actions because of her physical female body. In process of expressing the sexual violence she experienced, the blame for violence was placed back onto Devon because of a heteronormative societal expectation of how men and women are supposed to behave together. Each of these unique stories carry similarities with one another in describing the dehumanizing, invalidating, humiliating impact of the violence and moving forward with feelings of guilt and shame. Although this study focuses on the transformative experience of drama and performance art, I highlighted these significant themes because they speak to how gender-based violence impacted these individual's lives. Moving forward I will discuss how drama and performance art transformed the lives of participants following violence.

\section{Barriers in seeking support: invalidation.}

Within this section I will explore the barriers participants faced in their efforts to seek, or choosing not to seek support, following experiences of violence. In this section I strive to illuminate what support services participants have accessed and how these services can be inadequate for people with diverse identities that experience gender-based violence. Following this, I will move into how drama differs from these support services. My intention is to recognize if any barriers exist within this context that could inform Anti-Oppressive social work practice, and how drama and performance art has reduced these barriers in participants lives to facilitate 
healing. Participants shared barriers they faced moving forward from experiences of violence and how this impacted their lives.

Amy discussed feelings of invalidation both within and outside of her home, which acted as a barrier in seeking support. In these continuous experiences of invalidation, she described feeling as thought she could not trust her own reality. Amy explained living with thoughts of suicide after multiple experiences of violence from her peers because of her gender expression. She explained feeling suicidal in middle school and how this persisted throughout high school. Amy specifically reflects on her experience of seeking support for thoughts of suicide and being invalidated when accessing the school guidance counsellor for support. This experience ultimately led to Amy being admitted into the hospital;

I tried seeing a counsellor, trying to tell them ... you know I wasn't in a good place and struggling with thoughts of suicide for years... and they accused me of creating false problems to see them. I stopped seeing the counsellor and it wasn't until I collapsed at school and went to the hospital and they saw the cuts on my leg where they were like "we need to intervene". I am very lucky that I didn't successfully kill myself at any point because I did make attempts, but my heart breaks for those that didn't [emotional crying] people definitely have fallen through the cracks because of this.

Amy describes her unfortunate experience in reaching out for help and support following numerous incidences of violence. Shortly after asking for support she became suicidal again, frequently moving in and out of hospital care being placed on various medications. Amy's experience speaks to a larger issue of institutional violence that many trans, queer, and gender fluid identified people face when accessing support services. These experiences of invalidation further marginalize and isolate people following experiences of violence, which act as a barrier in healing from violence. 


\section{Barriers in seeking support: fear.}

A second sub-theme that emerged in exploring the barriers in seeking support were feelings of fear from participants. Devon described struggling to share her experiences of violence, and similar to Amy, connects this to being frequently discredited by others based on her identity;

I mean first of all ...telling somebody that they did something wrong ... when you think you could be wrong about it... you can't take that back...so you have to be so fucking sure of how you feel. What's so scary about that is that as people with vulnerabilities, as marginalized people we have been taught not to believe ourselves, we have been taught to discredit our own intuition about things. Even if something feels wrong. I think more than anything we're afraid to be wrong. Were afraid of ... saying things that were not going to be able to take back (Devon).

Devon explains the feeling of questioning herself and the violence she experienced. She highlights an important point, which is that people who experience frequent marginalization in society feel as though they don't have the power to challenge violence. More specifically, people experience a fear of being wrong about their own experiences because they are so frequently discredited when they share them with others.

\section{Barriers in seeking support: shame.}

Similar to both Amy and Devon, Sheela described feeling apprehensive about seeking support for the violence she experienced with her ex-partner due to feelings of guilt and shame;

I accessed mental health services for the anxiety that those problems were giving me, but it never even crossed my mind to reach out to somebody about the position I felt trapped in. I think a lot of women and people who are in abusive situations think it's their fault. There was a level of shame that I would allow somebody to treat me like that. The emotional abuse, being gas lit for years makes you second guess everything. Over time you start to believe it. It's hard to keep that part of yourself, it chops that part away.

Sheela identified a loss of self through her abusive relationship and how that contributed an additional barrier to challenging violence. Every participant shared stories of struggling to challenge violence and access support due to feelings of guilt, shame, fear and invalidation. 
Their experiences of violence influenced every person to second guess or question their own experiences. Sheela connects this further to how society reinforces a victim-blaming narrative, which reinforces feelings of guilt and shame, making it increasingly difficult for survivors to share their stories;

You know what are we fed through the media about battered women? "Oh, why do they stay...oh they're weak and they're victims" You know I was a victim of that for sure, it had nothing to do with weakness. When I was in the violence and in those relationships... it feels so normalized. Fighting felt very comfortable for me, it felt like home to me because that's what I saw all the time [...] I guess that's a barrier. Not having the tools to be able to recognize that this isn't healthy.

Sheela describes learning that violence was a normal component of relationships throughout her life. This normalization of violence acted as a barrier that made it increasingly difficult for her to seek support outside of her relationship. In order to survive experiences of violence, people frequently normalize it to ensure their safety and move forward from those experiences. When this normalization is then reinforced by other relationships in one's life such as family, friends, coworkers, media, it can make it impossible to share experiences of violence to receive support. Through understanding the impacts of gender-based violence on participants and the barriers they faced in an effort to seek support, I will now move into a discussion of how drama contributed to the lives of participants following these experiences to illuminate what makes this process unique for survivors.

\section{Experience of drama and performance art: empowerment.}

In this section I will explore the major themes that arose in participants discussing their experiences of drama and performance art. I explore how participants understand drama and performance in relation to their experiences of gender-based violence, to determine what makes this process unique for survivors. I illustrate how participants interpret their experiences of drama and how this process impacted different areas of themselves and their lives. Throughout 
this discussion, I identify themes within the narratives that could inform Anti-Oppressive social work practice. Each participant accessed drama in different settings and engaged in different methods of art from one another. Despite the differences in experiences, they share common themes in describing the impact drama had on their lives. The first theme highlighted in this section will be empowerment.

Amy recalled early experiences of participating in school plays as a kid and specifically recalls a play she did in grade seven, during a time when she was experiencing violence from her peers and struggling with thoughts of suicide. Amy describes the impact of participating in this play; "I just remember how everyone was like "wow you shine, this is you, this is what you're supposed to be doing" ....it just felt so empowering". Similarly, Devon explained how drama and performance art have always been an integral part of her life. Despite the significant presence of drama in her life, Devon shared how the process shifted when she faced experiences of gender-based violence. She describes moving forward from her first experience of genderbased violence and how her relationship with art shifted as she utilized drama and performance to process the violence she experienced;

I basically ruined my life after that. I started getting deeper into darker forms of art ... But it was important for me to be a really resilient, badass, rock chick, because that was... the most empowering thing I could do for myself. For a long time, I think I was making art that just like wasn't true. Because I couldn't face my own truth. And now I feel like I'm making art from a perspective that...explores all of those areas. I think a lot of people go through guilt... and shame [...] I definitely felt like a lot of things were my fault. If you're experiencing gender-based violence, the common denominator is you.

I thought it was important to highlight Devon's experience of gender-based violence having an impact on her relationship with drama and performance. She stated that feelings of guilt and shame strongly influenced how she expressed herself through art but describes how she was able to access feelings of resiliency and empowerment. Similar to both Amy and Devon, 
Sheela identifies her relationship with burlesque as one of empowerment, as it allowed her to move forward following the violence she experienced with her ex-partner. Sheela became connected to the burlesque scene following the end of her relationship, and describes burlesque as a cathartic outlet moving forward from a relationship of violence;

I've always been in drama and singing since I was a little kid, the burlesque part happened after I got divorced. I was dancing, and this woman approached me and was like "have you ever thought about doing burlesque?" I was separated at that point, and after going through this period where I had to dull every part of myself or I would get in shit for it, I would have a lot of stress in my life, so I wasn't performing. I had years of not being able to do that and finding something like that was very cathartic and helpful to be ramping out of that low point...

Similar to Sheela's experience, Devon describes feeling empowered through finding a

performance scene that allows for her to embrace all the intersections of her identity,

I've experienced so much empowerment from being in this scene because I am back to not feeling a woman, I am back to feeling like a person. And... that is a very specific feeling that I don't think I have ever verbalized actually. I don't make art thinking about you know am I gonna look good doing it and like am I going to be respected by men doing it. Performance art has made me look at my body and think what can it do? Not, what does it look like? That has been the most freeing thing. I've seen art transform people in that way so many times. Its relentless...its incredible every single time.

In this quote, Devon realizes the impact of drama and performance art as both empowering and transformative. She explains how finding this community has allowed her to free herself and describes the ability of drama to unlock people from the confines of their bodies and the societal expectations that surround them.

\section{Experience of drama and performance art: representation.}

As Amy moved into high school and strived to express her femininity as a trans woman within the confines of a physically male body, she increasingly experienced violence, which prevented her from accessing drama. However, Amy discussed her relationship with drama 
shifting when she came out publicly as trans. Amy explains the significance of trans visibility

and the impact this had on her life and her connection to drama and performance art;

Between understanding the term trans and then recognizing that was me and being like this is something I need to claim and be out if I'm going to have a life I am not wanting to end. I was doing a ton of research, trying to understand other experiences, constantly seeing people not having happy outcomes, which was largely why I didn't want to come out. Once social media came out, I started watching YouTube, and now there is countless trans people that I follow online and having seen their experiences led me to think what an awesome form of art to be able to look back on your own experience.

Amy described the moment of finding YouTube as life changing. YouTube provided a video platform where she was able to view positive lived experiences of trans people, when this wasn't something she had access to before. Amy discusses the accessibility of this platform to use drama and performance art online to document her own transition. Amy realizes in her reflection below how important it was for her to put her own personal experiences online for others to connect with and know they are not alone in their experiences;

When I started transitioning was when I knew I wanted to document my transition, it is very much curated, you know its performance mode. My videos start as like monthly updates, talking about the experiences that I was feeling through transitioning. I thought it would be really cool to do like skits and scenarios around trans experiences. So that way even more trans people can come to understand it, cis people can come to understand our experiences better as well [...] I thought would be helpful for people to know about my experience and feel validated in knowing that they're not alone, because I know how important that is.

Amy's experience with YouTube speaks to the importance of visibility of people that are frequently marginalized by society based on components of their identity. To view an experience that represents one's identity provides an opportunity for connection, reminding people they are not alone, which can help survivors that often experience feelings of isolation. In all of the participants stories of performing, they shared the significance of representation. Amy describes visibility as being the whole basis of what she is doing on screen and explained the basis of being on a screen is to create validation for other trans people and for people in general to see that there 
are trans people who have happy lives. Sheela also discussed the importance of representation

within burlesque and the powerful impact this has;

We're doing burlesque in bodies that you wouldn't normally see. To me representation is really important, having people of colour in shows, having trans bodies in shows, having people in staring glamourous roles that you don't see anywhere else [...] I think when you're bearing something that your whole life you have been told never to show to anybody, is a very powerful thing. Not just for you but the people who look like you who are watching you do that. It's really a powerful moment.

Sheela highlights the power in showing diverse bodies on stage and the significance of including people with many intersecting identities. She explains how this not only impacts the people performing in the burlesque shows, but people watching who identify with those performers.

\section{Experience of drama and performance art: coping skills.}

In discussing their experiences of participating in drama, each participant highlighted using drama techniques as tools to combat barriers and incidences of violence. Amy describes experiences of violence within the school system, while Devon and Sheela comment specifically on experiencing violence from men when giving performances on stage. Devon reflected on one of her recent experiences of violence while she was performing and the way she strives to combat violence through her performances;

I went on the stage and during this really intimate song, a guy yelled "Nice tits!", and I couldn't believe I was back to thinking about....my body... when I'm up there, connecting with...so many levels of internal psychology. I have learned more that it is really about owning the space. If you go up there and you make it apparent what you will tolerate and what you will not, what you are emoting, what performance you want to give and what you want people to take away from it people will listen.

Devon recalled how this incident interrupted the process of her performance and brought her back to how other people view her body. She said these types of experiences happen frequently and she has developed skills through performing that allow for her to own the space 
that she is in and combat violence. Similar to Devon, Sheela reflected on numerous experiences of violence she has encountered while she has been performing burlesque shows and how she has developed to combat violence in front of a live audience;

There have been multiple times when I have been performing, where men will come up on stage and they will want to touch me. I have been groped while I was singing. And having to deal with that in a room full of people? Not only that but a room full of other men who thought that was funny? Because it's a woman being sexual. I was angry, you have such a low opinion of me, such a dehumanizing view of me. Being pulled out of feeling powerful and being in control because someone is coming in and invading my area, so I've developed skills to not break my character.

Sheela details multiple experiences of various forms of violence from performing as a burlesque dancer. She explains feeling as though she places herself in a vulnerable position where she is more likely to experience violence because she is a woman openly expressing herself sexually. Sheela feels others frequently view that as an invitation for violence. Similarly, Amy faced increasing barriers as she entered puberty and faced exclusion due to her gender expression. She reflects having a strong desire to join drama in high school and explained that numerous acts of violence were a major barrier preventing her from following her passion for drama. However, like the other participants, Amy recognized the importance of creating and owning space. She said YouTube became a safe forum where there was visibility and representation of people with similar experiences to her. Amy recalls the strong impact of joining YouTube creating performances that shaped her life;

At the end of the day why am I waiting to do acting through like a class or on stage when I could just do it through YouTube? As my confidence is building you know I'm feeling more and more validated through my journey and it's given me a huge space for me to be like I'm turning this into what I want, I am the creator of my own destiny.

Amy describes the validation she felt in finding a platform where she could be herself and create her own performances. She also highlights the flexibility of online platforms, such as 
YouTube, in providing spaces for people who are frequently marginalized can guide their own performances to share with others.

\section{Experience of drama and performance art: connection to self and others.}

The final theme discovered in exploring the process of drama and performance art was its ability to facilitate connection. Participants describe how participating in drama allowed for them to connect to parts of themselves they had neglected, suppressed, or ignored due to experiences of violence. In addition, every participant explained how drama created a space where they could connect to others. Amy described the process of curating her YouTube performances and the impact of sharing this with others in an online forum. She explains having to first understand herself before she is ready to share with others;

Honestly, the one thing that really is astounding for me doing YouTube, is that it is a safe space for me to explore my own experiences. Because before I can put anything out there for anyone else to understand, I have to reconcile it for myself. So now I have created a need in my own life for me to have this safe space where I can truly understand what I'm going through to a point where I can share it with others.

Amy highlights an important point that connects with many key themes, such as the process connecting in with herself and her own experiences in order to be able to share them with others. In the process of creating her performance, she first needs to understand herself and once she understands herself she can share it with others. Devon also highlighted connection to herself as a significant part of the dramatic process and relates it to having the ability to break assumed gender roles. She explains how drama can be a catalyst that allows you to access uncomfortable emotions;

In drama you are...taught how to break down your feelings, you have to explore them in order to project them. Men in society have not been taught how to talk, in drama you have to talk about it, because you have to talk about the feelings of the characters. That teaches you how to access those emotions. I think if anything ...everybody should do a little bit of performance art because it teaches you that your emotions and your feelings 
and your experiences are malleable you can touch them and understand them, project them and connect using them. And I think that is a life skill that has expanded my world.

All participants shared how they suppressed uncomfortable emotions such as shame, guilt and fear following experiences of violence. Devon explained how drama and performance can allow for you to connect to yourself and your emotions and highlights this as a life skill. Sheela also expressed that burlesque is a platform where she has been able to reconnect with parts of herself that she earlier suppressed in her abusive relationship. She described the impact of burlesque on her relationship with herself;

Feeling after so long having to suppress that side of myself. It's a place where I always feel successful, that I know I am very good at, where I feel powerful and in control. I am playing a character that is kind of like me just exaggerated. It's a persona that is an escape, you know for a lot of women feeling like your sexuality is repressed, controlled or feared or used against you in a lot of ways. As a performer I am in control of that. I am up on a stage because I want to be there. You know burlesque is stripping, it can be funny, silly, cutesy, erotic, and sensual. It can be all of those things. Embracing those parts of myself, was amazing.

Sheela discussed the significant impact of burlesque and its ability to provide an escape where she can access new parts of herself and gain self-control that she felt she lost in her relationship of violence. Devon connects her experiences performing to its ability to connect her to not only her own experience, but with others, and how this can be used for coping with experiences of violence;

I think you can learn a lot about yourself through exploring someone else's perspective. Because you see parts of yourself in somebody else. You identify it, see the way that person works through it and gain knew knowledge about how to cope. I think that taking myself out of my own shoes and putting them in someone else's, whether I've designed that character myself or someone has given me that role. [...] It gave me a lot of power to feel like I could. And that gave me confidence to feel like I could.

Devon shares the process of drama and that playing a character allows for her to connect and identify with someone else's experience. She shares how this process has given her confidence and power in her life, while gaining new knowledge about how to cope. Similarly, 
Amy shares how performing has allowed for her to regain confidence and parts of herself that felt lost from experiences of violence;

I would say confidence boost, I am really coming back into myself, which is something that really excites me. I love having also the ability to explore myself and have this platform where I can share that will others on a certain level. I love that connection piece. You know having that interaction with people, its one validating to be seen, two it's amazing to hear of the help I give others. Finding my way into YouTube has really unlocked my creativity again, and it's really refueled the machine of the artist that I am.

Amy discussed how YouTube provided a space where she can reclaim herself through her transition, while sharing this experience and connecting to others. These themes highlighted from the interviews with participants demonstrate the capacity of drama to transform lives. Every participant shared details about the powerful impact of drama. Each person discussed feeling as though performance has allowed for them to reclaim and connect to parts of themselves that they learned to suppress or hide due to experiencing violence. Participating in drama and performance allowed participants to exist outside of the confines of their assigned gender. Amy described her experience transitioning on YouTube as a "chamber of growth" and Sheela said that burlesque has been a "catalyst" for rediscovering herself. Devon said that performance has allowed for her to trust herself, rebuild confidence and connect to others.

\section{Drama and social change:}

A final theme that emerged in the interviews with participants was the ability of drama and performance to contribute to social change through resisting gender-based violence. Drama and performance art provides a creative platform where survivors can understand how their personal experiences connect to larger social issues. Amy shared how drama has the ability to bring awareness, visibility, and understanding because dramatic art is given more space and recognition in society; 
People are more likely to pay attention when they are being entertained or feel a connection, and dramatic art can facilitate this. Drama and performance art has the creative ability to present an issue from multiple perspectives. In relating this to genderbased violence, a performance has the ability to show viewers the perspective of a victim, bystander, assailant, or all three. This allows for people to connect deeper to an issue when they understand it from all perspectives. Additionally, it encourages people to consider the role they play in a larger social issue and how they can work in their own lives to make changes.

Amy highlights how drama is flexible in the ability to show multiple perspectives within one incident, which allows for one message to reach more people. She explains how drama can contribute to resisting gender-based violence in creating awareness about the role each person plays in one issue. Sheela described burlesque as a "tool to examine misogyny and violence" and that it can expose you to difference ways of battling these issues in your daily life. She explains that although people are going to a burlesque show to be entertained, they are also receiving political messages that encourage them to view the world more critically. Sheela highlighted the flexibility and accessibility of burlesque in reaching diverse groups because it is not as politically obvious as a protest, or march. Sheela shared how she believes performance allows survivors to heal from experiences of violence and contributes to social change;

I would say any kind of creative pursuit... it allows you more than anything to be present, and when you are doing something that you feel passion about, you are able to transcend that trauma. For me feelings of inadequacy, shame, those talking heads in the background, it silences them. When you are able to be present and connect with people in a meaningful way I think that strengthens your ability to connect with yourself. And for me really being able to... see the change in other women watching me do what I do, allowed me to really change that in myself.

Sheela highlights an important point of performance art allowing for her to "transcend her trauma". Through burlesque she was able to move forward, releasing feelings of violence and shame, while connecting with others that want to do the same. Devon shared a recent opportunity she had to write a piece about her experiences of gender-based violence, which was her first time publicly sharing this incident; 
It was so connecting. Women came up to me afterwards and were like "thank you so much for that I feel like I can take steps now". And that is probably one of the most rewarding things about art. It is transformative! It takes people from feeling like they aren't capable of contribution and it instills confidence in them that they are worthy.

In Devon's experience, through sharing her story of violence creatively in a public space for others to view she was able to connect to others that had similar experiences. She described how this allowed for people to understand their own experiences of violence, including feeling empowered to move forward from gender-based violence in their own lives. Among all participants unique experiences and stories, they highlighted the capacity of drama and performance art in facilitating solidarity among survivors which effects social change. 


\section{CHAPTER 6. DISCUSSION}

I began this research project striving to understand the transformative experience of drama and performance art with survivors of gender-based violence. I finish this paper with a rich empathetic understanding of the therapeutic potential of drama through the lived experiences of three survivors. In their journey of healing from experiences of violence, each participant shared unique stories of overcoming and empowering themselves in accessing different spaces to participate in drama. I was able to uncover how participants lives were impacted from the process of drama and performance and how this connected to their identity as a survivor of gender-based violence. Despite the unique identities and lived experiences of each participant, every person shared similar experiences of both gender-based violence and drama. The findings discovered in this research paper align with the themes highlighted in the literature review, while contributing to the existing gaps in the literature.

The first sub-theme discovered in exploring how participants understood and experienced gender-based violence was the issue of power imbalance. Participants explained how they believed gender-based violence, in all of its many forms, stems from the issue of unequal power based on gender within society. The theme of power imbalance in these research findings align with the reviewed literature in attributing gender-based violence to the unequal power relationship between two genders (Russo \& Pirlott, 2006; Terry \& Hoare, 2007; UNFPA \& WAVE, 2011).

A second sub-theme that was similar to the findings presented in the literature review, was the significance of gender norms and expectations in the issue of gender-based violence. In viewing gender-based violence from an Anti-Oppressive, intersectional, transfeminist framework I was able to highlight the experiences of survivors that identify as racial, gender, and sexual 
minorities. All participants self-identified as members of the LGBTQ community and a common theme in their discussion of gender-based violence was the issue of gender expectations and norms placed on their physical bodies. Participants shared experiences of feeling pressure to adopt socially prescribed gender roles. These findings share similarities to the reviewed literature in connecting the issue of gender-based violence to social gender norms and expectations. (Calton, Cattaneo \& Gebhard, 2016; Espelage, Merrin \& Hatchel, 2018; Edwards et al., 2015). Through utilizing an intersectional, transfeminist lens I empathetically uncovered the experiences of participants that do not identify as cis-gender. This allowed for me to highlight the experiences of gender minorities in exploring the issue of gender-based violence and connecting it to the transformative process of drama. In addition, I was able to highlight barriers participants faced in seeking support following experiences of violence. Amy particularly described numerous incidences of institutional violence from service providers due to her trans female body. Amy's lived experience connects to the findings presented in the literature review that highlight transgender and queer individuals may be at even higher risk of violence and victimization by others based on their gender identity (Calton, Cattaneo \& Gebhard, 2016; Charest, Kleinplatz \& Lund, 2016; Edwards, Littleton, Sylaska, Crossman \& Craig, 2016; Edwards, Sylaska, Barry, Moynihan, Banyard, Cohn, Walsh, Ward, 2015;Espelage, Merrin \& Hatchel, 2018; Langenderfer-Magruder, Whitfield, Walls, Kattari, \& Ramos, 2016; Status of Women Canada, 2017).

The reviewed literature discussed drama techniques through the structures of psychodrama, dramatherapy and theatre of the oppressed. The research findings presented in this paper highlight alternative settings where survivors choose to access drama. Amy specifically discusses the impact of performing on YouTube, Devon explores her experiences of being in a 
performance-based band, and Sheela shares the significance of burlesque. Through these research findings we can begin to understand the potential barriers that can exist for survivors in structured settings and create awareness about other accessible avenues for survivors to access drama.

Although every participant accessed different platforms for drama, they shared common themes in describing its impact on their life. The four sub-themes that emerged in understanding the impact of drama were representation, empowerment, coping skills, and connection to self and others. These themes are similar to the findings presented in the literature review, which discussed the ability of drama to be a creative outlet where participants could understand their own experiences, gain confidence, power, empathy and self-awareness, while connecting to others (Brigell, 2010; Carbonell \& Parteleno-Barehmi, 1999; Frisina, 2010; Giesler, 2017; Jarman, 2014; Kirk, 2015; Mackenzie, 2013; Nadeau \& Sajani, 2006; Rousseau et al., 2007; Saeed, 2015; Stahl, 2018; Testoni et al., 2015).

In the sub-themes presented in the research findings on the impacts of drama, participants described the importance of visibility and how drama created a platform where their experiences were represented. Each person described gaining feelings of empowerment through participating in drama and how this funneled into their daily lives. Participants explained the coping skills they gained through drama techniques, which allowed for them to heal and combat violence in their daily lives. Lastly, participants shared how accessing drama allowed for them to connect to new parts of themselves and others. Overall, this allowed for them to feel less isolated following experiences of violence.

A significant theme discovered in the narratives of participants, was the ability of drama to unlock participants from gender norms and expectations. Participants identified gender norms 
and expectations in their understanding and experiences of gender-based violence. Therefore, drama and performance functioned to release participants from social norms that perpetuated violence in their lives. Drama provided a platform where participants could define their own identities and make decisions about their own bodies, which is a primary principle that guides transfeminism (Koyama, 2001). Participants shared how they not only felt safe in spaces of drama to express their intersectional identities, but they gained skills to combat violence and discrimination in their daily lives.

In the last theme presented in the research findings participants shared how drama contributes to social change. Amy discussed the flexibility of drama in combating social issues, such as gender-based violence. She discussed how drama has the ability to show multiple perspectives, which can allow for more people to understand how they may contribute to violence and ways to change their behavior. Sheela and Devon highlight the capacity of drama to allow for survivors of violence to connect with one another and build solidarity to create change. These research findings are similar to the literature reviewed on Augusto Boal's Theatre of the Oppressed, which views drama as a platform where participants can build skills and language for social change (Brigell, 2010; Giesler, 2017; Midha, 2010; Saeed, 2015; Shawyer, 2011; Stahl, 2018). These research findings show the potential of drama to contribute to Anti-Oppressive Social Work Practice through challenging oppressive social structures that perpetuate issues such as gender-based violence (Bains \& Edwards, 2015; Wong \& Ying Yee, 2010). Overall, the themes in the research findings demonstrate the significance of creative outlets, such as drama and performance art, in providing a unique space where survivors can heal and move forward to resist gender-based violence in their daily lives. 


\section{Personal statement (Bracketing):}

Throughout my experience in conducting this research I uncovered a number of assumptions, biases and values I carry as a cis-white woman, that I was not aware of prior to writing this Major Research Paper. In reflecting on the beginning of this research inquiry, I recognize that I arrived with a very narrow understanding of what gender-based violence can look like. The process of conducting this research challenged my perception of where violence can take place and who this ultimately impacts within society. I am grateful for the opportunity to have learned from Ryerson Social Work professors, my classmates, peers, research literature, and most importantly the experiences of survivors who transformed the way I view an issue that I am very passionate about. In receiving this critical knowledge and coming out and into my own identity as a queer woman, I feel released from many of the heteronormative assumptions I carried.

Following these experiences, I shifted my understanding of gender-based violence to view it from an Anti-Oppressive, intersectional, transfeminist framework, which greatly shaped my interpretation of the data gathered for this research. I realized the many different ways and forms of violence people experience based on intersections of their identity that are different from my own. Overall, this shifted the way I understood the unique experience of drama and performance art with survivors of gender-based violence. I arrived with an assumption that drama was a positive, transformative experience for participants because that was what I discovered when I participated in it. However, through reviewing the research literature and meeting with survivors I realized my understanding of the capacity of drama was limited. I initially arrived in this research project with a very individualistic, therapeutic, comprehension of drama. 
Upon completing this research, I was surprised by the potential of drama, and how it is currently contributing beyond the individual and to the larger community, resisting social issues such as gender-based violence within society. Drama and performance have the creative ability to reach people beyond a clinical, classroom, or theatre setting and into the online world through platforms such as YouTube. The flexibility allows for people with unique identities to feel safe in accessing spaces where they can watch people representing lives similar to their own, which is not always available in mainstream settings. In reviewing the audio-recordings and written transcripts multiple times, I realized I missed links in research findings due to my assumptions and biases. For example, when participants shared their experiences of meeting barriers, including gender-based violence, within a drama setting I viewed participants stories as experiences of gender-based violence. However, went reviewed the transcripts and re-read quotes from participants I realized their stories highlighted strength, including coping skills they developed to combat gender-based violence through drama, which was a major theme in the data.

Furthermore, I did not anticipate discovering a strong theme of gender norms and expectations in both the literature review and findings for both gender-based violence and drama. Participants shared stories of how drama and performance unlocked them from gender norms and expectations they faced in their daily lives. When I reflected on this theme I connected it to my own participation in drama and realized that I shared an experience similar to participants. Overall, the continuous process of uncovering my assumptions, biases and values throughout this research project reshaped the way I view both gender-based violence and drama and performance art; ultimately impacting the research findings to my research inquiry of: what is the unique experience of drama and performance art with survivors of gender-based violence? 


\section{Limitations:}

A number of significant limitations arose throughout this research study. A major limitation to this research was the short time frame, as both recruitment and interviews were conducted between the end of March 2018 and beginning of June 2018. The sample size of selected participants was three. However, the purpose of this research study was to gain a deeper understanding of the experience of drama and performance art with survivors of gender-based violence. If there was a significant increase in participants recruited it may have impacted the qualitative nature of this research but having a higher sample size could have generated findings that were richer in detailing survivor's experiences of drama.

Furthermore, although the interviews strived to facilitate natural dialogue between myself and the participants, a majority of the research findings derived from the set of open-ended interview questions posed to participants. I created the set of interview questions and within my interviews with participants I maintained space for each person to guide their own stories. However, there were numerous times in each interview where I posed questions to participants to ensure all research questions were answered. As a result, my assumptions, values, and biases naturally influenced the interview, transcribing and thematic coding within this research study.

Another limitation was the criteria requirement for participation in the research study. It was required that participants identified as having experience(s) with gender-based violence and participation in drama and performance art. Although these requirements were obligatory in order to understand what makes the experience of drama unique for survivors, people may have felt apprehensive in identifying as a survivor of violence. Gender-based violence can be a sensitive or triggering topic for many people, particularly survivors, which may have impeded their ability to participate in this research study. 
Lastly, this research study required that participants have experience participating in drama and performance art in a variety of settings. Although this allowed for more people to be eligible to participate and allowed for a wide range of different experiences of drama and performance, it did not focus on a specific form or dramatic technique. Future research on this study should carefully validate and understand the vulnerabilities of survivors of gender-based violence in choosing to take part in research. Taking into consideration the potential resources and supports survivors may need following any discussion that may connect to their experiences of violence. 


\section{CHAPTER 7: IMPLICATIONS \& CONCLUSION.}

In this section I will discuss the themes that emerged within the research findings and how they can provide insight for Anti-Oppressive Social Work Practice, specifically in supporting survivors and resisting gender-based violence. I begin by highlighting that every participant in this research project shared experiences of struggling to access services and support following their experiences of violence. They discussed feelings of invalidation, fear, guilt and shame. Specifically, Amy's experience as a trans woman faced multiple forms of institutional violence from service providers when attempting to seek support. Amy felt continuously invalidated from service providers, which created barriers in moving forward from experiences of violence and coming into her identity as a trans woman. Service providers for survivors of gender-based violence need to become better equipped in meeting the needs of LGBTQ survivors, particularly trans people. This is an important implication for AntiOppressive Social Work Practice, as it is documented in both the review of literature and the findings within this research study.

Furthermore, this study highlighted the barriers that exist and the capacity of drama to combat these barriers and facilitate social change. From the findings of this research study, creative ideas and techniques can be drawn out and applied to enhance Anti-Oppressive Social Work Practice, which can inform how social workers operate within clinical settings and the larger community. My intention is to contribute additional knowledge into a larger very important conversation or inspire more social workers to do the same. Moving forward as social workers it is important to consider all of the many ways people can heal, including creative modalities such as drama and performance. 
These research findings contribute to Anti-Oppressive Social Work Practice, as they highlight the flexibility of drama to be used for a number of goals. It is clearly demonstrated through the review of literature in settings using dramatherapy, psychodrama and theatre of the oppressed that drama techniques hold therapeutic potential for survivors. This research project builds on this understanding to view the transformative experiences of drama in the community and for it to allow for participants to regain power and self-determination in healing from violence. Anti-Oppressive Social Work should consider the therapeutic potential of drama and performance art and how this exists within and outside of prescribed therapeutic settings. Organizations, specifically those who support survivors of gender-based violence, should consider supporting drama and performance art as a tool for survivors to overcome and combat violence.

Drama is accessible for people with unique identities and abilities, allowing people to connect using creative methods of communication and expression. This functions to remove power differentials that can exist in therapeutic settings and function to oppress marginalized groups of people. The research findings presented in this paper highlight participants use of drama to determine their own healing from violence, with the ability to address structural problems, which is a key element of Anti-Oppressive Social Work Practice (Bains \& Edwards, 2015; Sakamoto \& Pitner, 2005). Future research on this topic with ample time and a larger sample size would be beneficial to understand the different settings drama is available to understand similarities and differences within these specific techniques. Overall, striving to understand how and where survivor's access drama and performance art therapeutically.

In my own experiences as a graduate-student and MSW candidate at Ryerson University, I chose to explore this research project for a variety of reasons. It was important for me as a 
survivor of gender-based violence, a participant in drama, and an Anti-Oppressive social worker to understand how all of my experiences and passions can inform one another. I wanted to contribute to a growing body of Anti-Oppressive Social Work Practice and literature, more specifically to build on a foundation of research that provides insight into the potential of creative interventions, such as drama and performance art.

As an Anti-Oppressive Social Work researcher, I believe it is necessary to not only consider how these research findings inform individual practice, but how they contribute to social change. I intend to continue broadening the ideas of what social work intervention can look like, specifically when supporting survivors of violence. It is important to continue the conversation about gender-based violence and understand how drama and performance art can provide a large platform to facilitate these conversations and create connections. I hope to contribute to the foundation of this research and for it to be built upon moving forward, while centring the experiences of survivors in order to have the opportunity to express their feelings, opinions and concerns on an issue that impacts them directly. I am grateful for the opportunity to conduct research that I feel very passionate about and meet with survivors who so graciously shared their own experiences and knowledge. I hope this research continues to expand and social work and drama and performance art continue to enhance one another. 


\title{
APPENDICES
}

\section{PARTICIPANTS NEEDED FOR RESEARCH}

\author{
Do You:
}

- Self-identify as female, trans, gender queer or gender non-conforming?

- Have past/present experiences in drama and performance art?

- Have you experienced gender-based violence?

- Are you the age of 18 or older?

- Are you willing to express your views about drama and performance art in relation to your experience of gender-based violence?

If you answered yes to the above questions, you are invited to volunteer in this research study. This research will seek to understand the transformative processes of drama and performance art for people that have experienced gender-based violence. Gender-based violence involves the use and abuse of power over another person. This violence is directed against someone based on their gender identity, gender expression, or perceived gender. Gender-based violence can include any act that results in physical, sexual, mental, and emotional harm and suffering. Participants will not be asked to share any details of their trauma or violence.

Rather, questions will explore participants' involvement in drama and performance art and how this has influenced their lives in relation to their experience(s) of violence.

You will be asked to participate in an in-person interview to discuss your experiences with drama and performance art. The questions in this study will not ask you any details of the gender-based violence you experienced. Your participation will involve approximately 45-1.5 hours of your time. There is no follow-up required for this study.

If you are interested in participating in this study or for more information, please contact:

\author{
Michelle Crozier \\ MSW Candidate, \\ Ryerson University, School of Social Work \\ mcrozier@ ryerson.ca
}

If you have concerns about this research study, please contact:

\author{
Dawn Onishenko, $\mathrm{PhD}$ \\ Ryerson University, School of Social Work \\ donishenko@ ryerson.ca \\ 416-979-5000, ext. 4792479
}

This study has been reviewed by the Ryerson University Research Ethics Board. If you have questions regarding your rights as a participant in this study please contact:
Research Ethics Board
Ryerson University
350 Victoria Street
Toronto, ON M5B 2K3
416-979-5042
rebchair@ryerson.ca

c/o Office of the Vice President, Research and Innovation

This research study has been reviewed and approved by the Ryerson University Research Ethics

Board 


\section{Facebook Post:}

Hi Folks,

I am currently a Master's of Social Work student at Ryerson University. As part of my graduate studies I must complete a Master's Research Project. My research explores the transformative process of drama and performance art with survivors of gender-based violence in Canadian society. I will be collecting data through conducting interviews either in person, by phone, or via skype with people that fit the criteria listed below. Please find the attached poster below with more information about the research study. If you feel that you meet the criteria and would like to participate in an interview please email me directly. The interview and information collected from the interview will be confidential. There is no obligation for anyone to participate. If you have any questions please contact me through my Ryerson email.

Thank you all,

[insert recruitment poster]

Michelle Crozier

MSW Candidate, Ryerson University

mcrozier@ryerson.ca

\section{Email to local theatres/community organizations:}

Hi there,

My name is Michelle Crozier, I am currently a graduate student at Ryerson University in the Masters of Social Work program. I am contacting you in regards to my Masters' Research Project with the hope of finding people willing to participate in a research opportunity. My research will explore the transformative process of drama and performance art with survivors of gender-based violence in Canadian society. I will be collecting data through conducting inperson interviews with people that fit the criteria listed below. Please find the attached poster below with more information about the research study. I would like to kindly ask if your organization could share this information for potential participants in your organization to see. I would greatly appreciate your participation in my research project. If you have any questions at all please do not hesitate to contact me.

Thank you for your time and consideration.

Kindest regards

Michelle Crozier

MSW Candidate, Ryerson University

mcrozier@ryerson.ca 


\title{
Ryerson University Consent Agreement
}

You are being invited to participate in a research study. Please read this consent form so that you understand what your participation will involve. Before you consent to participate, please ask any questions to be sure you understand what your participation will involve.

\section{Study: Understanding the Transformative Experiences of Drama and Performance Art with Survivors of Gender-Based Violence.}

INVESTIGATORS: This research study is being conducted by Michelle Crozier, MSW candidate and supervised by Dawn Onishenko, $\mathrm{PhD}$ from the School of Social Work at Ryerson University.

If you have any questions or concerns about the research, please feel free to contact:

\author{
Michelle Crozier \\ MSW Candidate, \\ Ryerson University, School of Social Work \\ mcrozier@ryerson.ca \\ Dawn Onishenko, $\mathrm{PhD}$ \\ Ryerson Unversity, School of Social Work \\ donishenko@ryerson.ca \\ 416-979-5000, ext. 4792 \\ Research Ethics Board \\ c/o Office of the Vice President, Research and Innovation \\ Ryerson University \\ 350 Victoria Street \\ Toronto, ON M5B 2K3 \\ 416-979-5042 \\ rebchair@ryerson.ca
}

PURPOSE OF THE STUDY: This study will strive to understand the transformative process of drama and performance art for people that have experienced gender-based violence in Canada. Gender-based violence involves the use and abuse of power over another person. This violence is directed against someone based on their gender identity, gender expression, or perceived gender. Gender-based violence can include any act of violence that results in physical, sexual, mental, and emotional harm and suffering. Participants must be the age of 18 or older to participate and be a survivor of gender-based violence. Participants must self-identify as female, trans, gender queer or gender non-conforming. The desired sample size is 3-5. The results of this study will be used for Michelle Crozier's Major Research Paper, which is a required component in the completion of her Masters of Social Work degree. 
WHAT YOU WILL BE ASKED TO DO: If you volunteer to participate in this study, you will be asked to do the following things:

- Provide consent by signing this form after being informed of confidentiality and the researcher answers any questions or concerns you may have.

- Participate in an in-person interview, approximately 45-1.5 hours in length with the primary investigator Michelle Crozier.

- Participants are not required to share any details of their experiences of trauma/violence

- In understanding violence is experienced differently based on a person's gender identity, sexual orientation, disability status, racial background and socioeconomic status, participants will be asked to report this demographic information.

- Answer open-ended questions from your own perspective and based on your own experiences and opinions.

○ Questions may include: What is your understanding/experience of gender-based violence? How did you become involved in drama and performance art? Can you describe the type of drama and performance art you participated in? Did this process impact you in any way in relation to your experience(s) of violence?

- After your participation, you can contact Michelle Crozier by email for any follow-up question or concerns you may have.

- Research findings will be available upon completion through Ryerson University's Master of Social Work website.

\section{POTENTIAL BENEFITS:}

- Participants may experience validation and understand the importance of their experiences, opinions, values, and beliefs.

- Participants can contribute valuable knowledge about drama and how it is used to respond to the social issue of gender-based violence

- Participants will have a confidential space to share their personal experiences in an inperson interview

- Participants will have the opportunity to provide suggestions and feedback at the end of the survey.

\section{WHAT ARE THE POTENTIAL RISKS TO YOU AS A PARTICIPANT:}

This is a low-risk research study, however there is a risk of discomfort and anxiety from answering personal questions and/or reflecting back on personal experiences when answering certain questions surrounding gender-based violence. Due to this potential risk, there will be a list of Toronto resources provided at the end of the interview. If you experience these emotions, you may skip the question temporarily or permanently, or withdraw from the study with no consequences.

\section{STUDY LOCATION:}

The interview will be conducted in-person in a private room located at Ryerson University in the SLC building. 


\section{CONFIDENTIALITY:}

Information shared throughout the interview will be removed of any identifying factors. Data collected will not be released to any other persons and will only be seen by the researcher Michelle Crozier and supervisor Dawn Onishenko. Your name will be removed from data during the data analysis phase of research and a pseudonym will be used. All other identifying information will also be removed.

\section{DATA STORAGE}

This consent form will be stored in a locked filing cabinet in the principle investigators home, where only the principle investigator Michelle Crozier will have access to it. With your consent, this interview will be recorded. The interview will be audio-recorded and stored in an encrypted file on a password-protected computer, stored in the principle investigators home. The principle investigator will have access to audio recordings and the transcribed data. The principle investigator may share audio recordings and transcribed data with the research supervisor, Dr. Dawn Onishenko. Audio recordings will be destroyed upon transcription of the interview. The transcribed data will be destroyed upon submission of the final major research paper. Research data will be retained until October 2018, after final submission of the major research paper, after which time it will be destroyed. Electronic files will be deleted and this consent form will be shredded. Research data may be shared with the research supervisor, Dr. Dawn Onishenko. No other individuals will have access to research data.

\section{DISSEMINATION:}

The final major research paper will be available through Ryerson University's MRP (major research paper) repository. This will be available via the following link:

http://digital.library.ryerson.ca/islandora/search/ $\% 3 A^{*}$ ? f[0]=mods extension degree departme nt $\mathrm{ms} \% 3 \mathrm{~A} \% 22$ Social\% 20 Work\%22

\section{COSTS TO PARTICIPATION:}

There are no costs to participate in the interview.

\section{COMPENSATION FOR INJURY:}

By agreeing to participate in this research, you are not giving up or waiving any legal right in the event that you are harmed during the research.

\section{VOLUNTARY PARTICIPATION AND WITHDRAWAL:}

Participation in this study is completely voluntary. It is your choice as to whether or not to participate in this study. If at any point during the interview you experience feelings of discomfort you can temporarily skip, or skip any question altogether. You can stop the interview at any time and will still be provided with a list of resources. If you decide to stop participating in the interview, your information will not be processed or used for the final research paper. The choice of whether or not to participate will not influence your future relations with Ryerson University or the investigators Michelle Crozier and Dawn Onishenko involved in the research.

QUESTIONS ABOUT THE STUDY: If you have any questions about the research now, please ask. If you have questions later about the research, you may contact: 


\author{
Primary Researcher: \\ Michelle Crozier, BSW \\ MSW Candidate \\ School of Social Work \\ Ryerson University \\ 350 Victoria Street \\ Toronto, Ontario \\ Canada M5B 2K3 \\ mcrozier@ryerson.ca
}

Supervisor:

Dawn Onishenko, PhD.

Associate Director, Undergraduate Program and Associate Professor

School of Social Work

Ryerson University

350 Victoria Street

Toronto, Ontario

Canada M5B 2K3

Tel: 416-979-5000, ext. 4792

donishenko@ryerson.ca

This study has been reviewed by the Ryerson University Research Ethics Board. If you have questions regarding your rights as a participant in this study please contact:

Research Ethics Board

c/o Office of the Vice President, Research and Innovation

Ryerson University

350 Victoria Street

Toronto, ON M5B 2K3

416-979-5042

rebchair@ryerson.ca

Study: Understanding the Transformative Experiences of Drama and Performance Art with Survivors of Gender-Based Violence.

\title{
CONFIRMATION OF AGREEMENT:
}

By continuing past the consent form to answer the questions, you have indicated that you have read the information in this agreement and have had an opportunity to ask any questions you have about the research study. Your agreement also indicates that you agree to participate in the in-person interview and have been told that you can withdraw your consent to participate at any time. You understand that by accepting this consent agreement you are not giving up any of your legal rights. 
Participants Signature

Interviewees Signature 


\section{Interview Guide:}

Interview Guide for Understanding the Transformative Experiences of Drama and Performance Art for People That Have Experienced Gender-Based Violence

Preamble: Thank you for agreeing to be a participant in this research project. Before we begin, I would like you to know this interview will take approximately an hour in length. I also want to ensure you the information shared in this interview is confidential and that only myself and my research supervisor will have access to the information you provide. All identifying information will be removed before the interview is used. Before we begin, I would like to ask your permission to record the interview.

Throughout the course of the interview you may ask to stop the recording, skip a question or take a break. You can also terminate the interview at any point if you feel any discomfort or you decide you have changed your mind about being a part of this research project. If you decide to withdraw from the study all information collected up to that point will be destroyed.

I will start by collecting some demographic information from you and then will transition into qualitative questions. The reason for asking these demographic questions is because research has shown that gender-based violence is experienced differently based on a person's race, gender, sexuality, socio-economic status, and ability and I would like to have an overview of who the participants are for the research. This information will not be associated to you when I write the findings. Do you have any questions for me before we begin?

1. How do you identify in terms of your sexuality?

2. How do you identify in terms of your gender?

3. How do you identify in terms of your racial background?

4. How would you describe your current socio-economic status? 
5. Do you identify as a person with a disability?

I am now going to go into the qualitative portion of the interview where the questions will be more open-ended.

6. How would you explain gender-based violence and violence against women in Canada? Prompts:

- Do you believe this is an issue in Canada? Is it widespread?

- Do you think this issue is recognized as serious by Canadian society? If yes, how come? If no, why?

- Who do you think this issue primarily affects?

7. If any, through what venues did you access or receive information about gender-based violence/violence against women in Canada?

Prompts:

- Was this through social media? Educational institutions? Family/Friends? Workplace?

- What was the nature of this information? (facts, personal stories, etc.)

8. How did accessing this information impact your understanding of gender based violence?

\section{Prompts:}

- Did this increase your understanding? If yes, how? If no, why?

- Did you feel any emotional responses? i.e. anger, sadness.

9. For the following question, I am not looking for any details of trauma but trying to gain an understanding of the timeline between the violence you experienced and your participation in drama: At what time(s) in your life did you experience violence?

\section{Prompts:}

- A week ago, one year ago, childhood? 
10. Did you access any services/supports/interventions following this incident(s) of violence?

\section{Prompts:}

- If yes, what types of interventions did you access? i.e. counselling, group therapy, crisis lines, shelter, medical etc.

- If no, why?

11. If you answered yes to the previous question and have accessed supports/services/interventions, what impact did this have on your life?

Prompts:

- Were these services helpful or unhelpful? Why or why not?

- Did it allow for you to understand your experience of violence?

- Did it allow for you to connect with yourself and others?

- Did you see any changes in your overall life following this? (emotional, mental, physical etc.)

12. From your own experience, what do you think are the biggest barriers for people in accessing supports or services following an incident of violence?

Prompts:

- E.g. Feelings of shame, fear, lack of awareness of available programs, time management, physical location, finances

13. How and when did you become involved in drama and performance art?

\section{Prompts:}

- How did you find out about this? (friends, school, work etc.)

- What time was this in your life? (childhood, adolescence, adulthood) 
- Did you access drama through an educational setting, community theatre, drop-in centre etc.?

- Why did you decide to participate in drama/performance art?

14. Please describe the type/kind/method of drama and performance art that you participated in.

\section{Prompts:}

- Was this conducted in a structured setting (counselling, educational institution)?

- Was this conducted in an unstructured setting (community theatre, improv)?

- If you participated in both types, which one did you prefer? Why?

15. From your own experience, how would you describe the process of participating in drama and performance art?

\section{Prompts:}

- Was there anything in particular you liked or did not like about this process? i.e. connecting with yourself/others, creative expression etc.

- How did you feel when you were participating?

16. What was your most preferred or favourite component when participating in drama and performance art?

\section{Prompts:}

- Writing stories, role play, creative expression with self and others...

- If you do not have a preferred activity, why do you think this is?

17. Are you actively involved in drama and performance art?

\section{Prompts:}

- If yes, why?

- If no, why not? 
- Is this something you would participate in again if given the opportunity?

- Would you recommend drama and performance art to others?

18. Following participation in drama and performance art, did you recognize any changes in other areas of your life?

\section{Prompts:}

- If yes, what did this look like? i.e. emotional, physical, spiritual, mental, changes in relationships with self and others.

- If no, why do you think this?

19. From your experience, what do you think are the biggest barriers for people in accessing and participating in drama and performance art?

\section{Prompts:}

- Fear of trying something new, lack of awareness, financial, physical location etc.

20. In addition to drama and performance art, have you accessed any other creative outlets?

\section{Prompts:}

- i.e. creative art, music, recreational therapy, journaling etc.

21. From your experience, do you think drama and performance art is different from other creative outlets?

\section{Prompts:}

- i.e. creative art, music, recreation, journaling, etc.

- If yes, why do you think this is?

- If no, please explain.

22. If you had the opportunity, what would you tell a survivor of violence who is thinking of participating in drama and performance art? 


\section{Prompts:}

- Do you believe their experience would be the same or different from other participants...

23. From your own experience, how you think drama and performance art can or cannot contribute to social change; Particularly in relation to gender-based violence/violence against women in Canada?

Prompts:

- If yes, how?

- If no, why not?

- Do you see drama and performance art contributing to this already? How does this look?

24. Before concluding our interview, is there any additional questions or comments you would like to ask or add?

Thank you for your time. 


\section{Resource List:}

\section{Barbra Schlifer Commemorative Clinic (Toronto):}

The Barbra Schlifer Clinic offers legal representation, professional counselling and multilingual interpretation to women who have experienced abuse.

http://www.schliferclinic.com/

Phone Number: 416-323-9149

\section{Toronto Rape Crisis Centre/Multi Cultural Women Against Rape:}

http://www.trccmwar.ca

The Toronto Rape Crisis Centre/Multicultural Women Against Rape (TRCC/MWAR) is a nonprofit feminist organization committed to fighting violence against women and children. TRCC/MWAR provides a wide range of services to all survivors of sexual violence, their family members and friends including:

- Individual counselling

- Court support and accompaniment

- Advocacy/Activism

- Support groups

- Public education and workshops

- Information and referrals

- Prison support

- Latin American Womens program

24 hour crisis line: 416-597-8808

Business office: 416-597-1171

The 519:

The 519 is committed to the health, happiness and full participation of the LGBTQ community. We respond to the evolving needs of the LGBTQ community, from counselling services and queer parenting resources to coming out groups, trans programming and senior's support.

Phone: 416-392-6874

Email: Info@The519.org

http://www.the519.org

\section{Ontario Network of Sexual Assault/Domestic Violence care and Treatment Centres:}

Access to 35 Sexual Assault/Domestic Violence Treatment Centres across Ontario. Can locate a support centre in an area most convenient to you on the website under the services/find a centre section:

https://www.sadvtreatmentcentres.ca

Telephone: (416)-323-7327

Email: info@sadvtreatmentcentres.ca

\section{Assaulted Women's Helpline:}

The Assaulted Women's Helpline offers a 24-hour telephone and TTY (type text) crisis line to all woman who have experienced abuse. We provide counselling, emotional support, information and 
referrals.

http://www.awhl.org

Helpline, free at 1-866-863-0511 or TTY 1-866-863-7868.

Text \#SAFE (7233)

\section{Family Service Toronto:}

- Service Access Unit

Tel: 416-595-9618 to arrange an appointment with a VAW counsellor or register for an in-house group program;

- Janet Wilson, Manager, Violence Against Women and Healthy Families program

Tel: 416-755-5565 ext. 422 to receive information on other VAW related services and programs

- Dari-speaking counsellor

416-586-9780 ext. 427 for individual counselling and community-based programs for the Afghan community

- Tamil-speaking VAW counsellor

Tel 416-755-5565 ext. 525, for individual counselling and community-based programs for the

Tamil community

- Farsi-speaking VAW Counsellor and Community Facilitator

Tel: 6479600351 for individual counselling and

Tel: 416-586-9780 ext. 512 for community-based programs for the Iranian community

- Somali-speaking Community Facilitator

Tel: 4165852044 ext. 566 for community-based programs for the Somali community

\section{Jewish Family and Child Services of Toronto}

Jewish Family and Child Services of Toronto is a non-profit agency, consisting of social workers, child care workers, family life educators, therapists, counsellors, and foster parents. They provide family; child \& youth; and community services.

- $\quad$ http://www.jfandcs.com

416-638-7800 ex 6234

REB 2018-112

Project Title: Understanding the transformative experiences of drama and performance art for survivors of gender-based violence. 
Dear Michelle Crozier,

The Research Ethics Board has completed the review of your submission. Your research project is now approved for a one year period as of May 3, 2018. The approval letter is attached in Adobe Acrobat (PDF) format.

Congratulations and best of luck with the project.

Please note that this approval is for one year only and will expire on May 3, 2019. Shortly before the expiry date a request to complete an annual report will be automatically sent to you. Completion of the annual report takes only a few minutes, enables the collection of information required by federal guidelines and when processed will allow the protocol to remain active for another year.

Please note that REB approval policies require that you adhere strictly to the protocol as last reviewed by the REB. Any modifications must be approved by the Board before they are implemented. Adverse or unexpected events must be reported to the REB as soon as possible with an indication from the Principal Investigator as to how, in the view of the Principal Investigator, these events affect the continuation of the protocol.

Please quote your REB file number (2018-112) on future correspondence.

If you have any questions regarding your submission or the review process, please do not hesitate to get in touch with the Research Ethics Board (contact information below).

No research involving humans shall begin without the prior approval of the Research Ethics Board.

This is part of the permanent record respecting or associated with a research ethics application submitted to Ryerson University.

NOTE: This email account (rebchair@ryerson.ca) is monitored by multiple individuals. If you wish to contact a specific member of the Research Ethics Board, please do so directly.

Yours sincerely,

Zakiya Atcha, MSW

Research Ethics Co-Ordinator

on behalf of:

Dr. Patrizia Albanese, PhD

Chair, Ryerson University Research Ethics Board

(416)979-5000 ext. 6526

palbanese@soc.ryerson.ca

rebchair@ryerson.ca

http://www.ryerson.ca/research

Dr. Asher Alkoby, LL.B., PhD

Vice-Chair, Ryerson Research Ethics Board

(416)979-5000 ext. 2491

aalkoby@ryerson.ca

http://www.ryerson.ca/research

Toni Fletcher, MA 
Research Ethics Co-Ordinator

(416)979-5000 ext. 7112

toni.fletcher@ryerson.ca

Zakiya Atcha, MSW

Research Ethics Co-Ordinator

(416)979-5000 ext. 4841

zakiya.atcha@ryerson.ca

REFERENCE LIST 
Anderson, S. (2016). Stitching through Silence: Walking With Our Sisters, Honoring the Missing and Murdered Aboriginal Women in Canada. Textile, 14(1), 86-96. doi:10.1080/14759756.2016.1142765

Anonymous. (2008). Stolen Sisters: A Human Rights Response to Discrimination and Violence Against Indigenous Women in Canada. Canadian Women Studies, 26(3/4), 105-121. Retrieved from https://search-proquestcom.ezproxy.lib.ryerson.ca/docview/217442058?pq-origsite=summon

Arnd-Caddigan, M., Averett, P., \& Pozzuto, R. (2010). Teaching Human Behavior and the Social Environment to Enhance Students' Personal Epistemology. Journal of Human Behavior in the Social Environment, 20(8), 974-988.

Baffoe, M., Asimeng-Boahene, L. \& Ogbuagu, B.C. (2014). Their way or no way: "Whiteness" as agent for marginalizing and silencing minority voices in academic research and publication. European Journal of Sustainable Development, 3(1), 13-32.

Baines, D. (2017). Anti-Oppressive Practice: Roots, theory, tensions. In D. Baines (Ed.), Doing Anti-Oppressive Practice: Social justice social work ( $3^{\text {rd }}$ ed.) (2-29). Nova Scotia: Fernwood Publishing. 
Baksh, B.S. (2016). Clarity and confusion: Epistemological struggles with Islamic identity and secular education, Qualitative Social Work, 15 (5-6), 640-649.

Brigell, M. 2010. Participatory Theater and the Prevention of Gender-Based Violence. Advocates' Forum. University of Chicago School of Social Service Administration. https://ssa.uchicago.edu/participatory-theater-and-prevention-gender-based-violence

Boal, A. (2005). GAMES FOR ACTORS AND NON-ACTORS. (A. Jackson , Trans.). Taylor and Francis e-Library: Routledge.

Brownridge, D. (2003). Male Partner Violence Against Aboriginal Women in Canada. Journal of Interpersonal Violence, 18(1), 65-83. doi: 10.1177/0886260502238541

Calton, J. M., Cattaneo, L. B., \& Gebhard, K. T. (2016). Barriers to Help Seeking for Lesbian, Gay, Bisexual, Transgender, and Queer Survivors of Intimate Partner Violence. TRAUMA, VIOLENCE, \& ABUSE, 17(5), 585-600.

Carbonell, D. M., \& Parteleno-Barehmi, C. (1999). Psychodrama groups for girls coping with trauma. International Journal of Group Psychotherapy; New York, 49(3), 285-306. 
Charest, M. \& Kleinplatz, P. J. \& Lund, J. I. (2016). Sexual health information disparities between heterosexual and LGBTQ+ young adults: Implications for sexual health. The Canadian Journal of Human Sexuality 25(2), 74-85. University of Toronto Press. Retrieved July 21, 2018, from Project MUSE database.

Charmaz, K. (2017). The power of constructivist grounded theory for critical inquiry, Qualitative Inquiry, 23(1), 34-45.

Cheung, M., Alzate, K., \& Nguyen, P. V. (2012). Psychodrama Preparation for Internship. Field Educator; Boston, 2(2). Retrieved from https://search.proquest.com/docview/1561220396/abstract/5014678566C24BC9PQ/1

Chilisa, B. (2012). Whose reality counts? Research methods in question. In Indigenous research methodologies (pp. 73-96). Los Angeles: SAGE.

Colarossi, L. (2005). A Response To Danis \& Lockhart: What Guides Social Work Knowledge About Violence Against Women?. Journal of Social Work Education, 41(1), 147-159. Retrieved from https://search-proquestcom.ezproxy.lib.ryerson.ca/docview/209785280?pq-origsite=summon

Crenshaw, K. (1993). Mapping the Margins: Intersectionality, Identity Politics, and Violence Against Women of Color. Stanford Law Review, 43(6), 1241-1299. Retrieved from http://multipleidentitieslgbtq.wiki.westga.edu/file/view/crenshaw1991.pdf 
Creswell, J. W., \& Poth, C. N. (2018). Qualitative inquiry \& research design: Choosing among five approaches.

Dehnavi, S., Bajelan, M., Pardeh, J. S., Khodaviren, H., \& Dehnavi, Z. (2016). The Effectiveness of Psychodrama in Improving Quality of Life among Opiate-dependent Male Patients. International Journal of Medical Research and Health Sciences, 5(5), 243-247. Retrieved from https://doaj.org/article/31577ee38d1d4be9b38995366b2038e1

Dix, A. (2015). Telling stories: Dramatherapy and theatre in education with boys who have experienced parental domestic violence. Dramatherapy, 37(1), 15-27. https://doi.org/10.1080/02630672.2015.1055778

Dogan, T. (2010). The effects of psychodrama on young adults' attachment styles. The Arts in Psychotherapy, 37(2), 112-119. https://doi.org/10.1016/j.aip.2010.02.001

Edwards, K. M., Littleton, H. L., Sylaska, K. M., Crossman, A. L., \& Craig, M. (2016). College Campus Community Readiness to Address Intimate Partner Violence Among LGBTQ+ Young Adults: A Conceptual and Empirical Examination. Society for Community Research and Action, 58, 16-26.

Edwards, K. M., Sylaska, K. M., Barry, J. E., Moynihan, M. M., Banyard, V. L., Cohn, E. S., Walsh, W. A., Ward, S. K. (2015). Physical Dating Violence, Sexual Violence, and Unwanted Pursuit Victimization: A Comparison of Incidence Rates Among Sexual- 
Minority and Heterosexual College Students. Journal of Interpersonal Violence, 30(4), $580-600$.

Espelage, D. L., Merrin, G. J., \& Hatchel, T. (2018). Peer Victimization and Dating Violence Among LGBTQ Youth: The Impact of School Violence and Crime on Mental Health Outcomes. Youth Violence and Juvenile Justice, 16(2), 156-173.

Espineira, K., \& Bourcier , S. (2016). Transfeminism. Something Else, Somewhere Else. Transgender Studies Quarterly, 3(1-2), 84-93.

Fook, J., \& Gardner , F. (2007). Practising Critical Reflection . England : Open University Press.

Frisina, C. (2010). Reclaiming Ourselves: The Use of Drama Therapy to Re-conceptualize Identity In Women Survivors of Domestic Violence (M.A.). Concordia University (Canada), Canada. Retrieved from https://search.proquest.com/docview/807620821/abstract/C18B5A8E7E374FF5PQ/1

Giesler, M. A. (2017). Teaching Note-Theatre of the Oppressed and Social Work Education: Radicalizing the Practice Classroom. Journal of Social Work Education, 53(2), 347-353.

George, P. (2017). Critical arts-based research: An effective strategy for knowledge mobilization and community activism. In H. Parada \& S. Wehbi (Eds). Reimagining social work research. (pp. 57-69). Toronto: Canadian Scholars. 
Hofer, B. K. (2001). Personal Epistemology Research: Implications for Learning and Teaching. Journal of Educational Psychology Review, 13(4), 353-383.

Hunter, M. (2002). Rethinking epistemology, methodology, and racism: or. Is White sociology really dead?. Race \& Society, 119-138.

Jarman, S. (2014). The effectiveness of drama therapy for children who have witnessed domestic abuse. Mental Health Practice (2014+); London, 18(2), 19. https://doi.org/http://dx.doi.org.ezproxy.lib.ryerson.ca/10.7748/mhp.18.2.19.e925

Jenson, J. (2000). Backgrounder: thinking about marginalization: what, who and why? Ottawa: Canadian Policy Research Networks.

Kedem-Tahar, E., \& Felix-Kellermann, P. (1996). Psychodrama and Drama Therapy: A Comparison. The Arts In Psychotherapy, 23(1), 27-36. Retrieved from: http://peterfelix.tripod.com/home/Drama.pdf

Kirk, C. J. (2015). Dramatherapy with women survivors of domestic abuse: a small scale research study. Dramatherapy, 37(1), 28-43. https://doi.org/10.1080/02630672.2015.1101480 
Koyama, E. (2001). The transfeminist manifesto. In R. Dicker \& A. Piepmeir (Eds.), Catching a wave: Reclaiming feminism for the twenty-first century (pp. 244-262). Boston, MA: Northeastern University Press.

Langenderfer-Magruder, L., Whitfield, D. L., Walls, N. E., Kattari, S. K., \& Ramos, D. (2016). Experiences of Intimate Partner Violence and Subsequent Police Reporting Among Lesbian, Gay, Bisexual, Transgender, and Queer Adults in Colorado: Comparing Rates of Cisgender and Transgender Victimization. Journal of Interpersonal Violence, 31(5), 855871.

Landson-Billings, G. (2013). Critical Race Theory-What it is not! In Handbook of Critical Race Theory in Education (pp. 34-47). Routledge.

Lundell, I. W., Eulau, L., Bjarneby, F., \& Westerbotn, M. (2018). Women's experiences with healthcare professionals after suffering from gender-based violence: An interview study. Clinical Nursing, 27, 949-957.

Mackenzie, N. (2013). A brief exploration of the role of dramatherapy within a multi-modal arts therapy approach to working with children aged 4-14 years impacted by trauma. Dramatherapy, 35(2), 131-139. https://doi.org/10.1080/02630672.2013.823747

Midha, G. (2010). Theatre of the Oppressed A Manual for Educators. Center for International Education, 11, 5-68. 
Moore, J., Andersen-Warren, M., \& Kirk, K. (2017). Dramatherapy and psychodrama with Looked-After children and young people. Dramatherapy, 38(2-3), 133-147. https://doi.org/10.1080/02630672.2017.1351782

Neuman, W.L. (2006). The meanings of methodology. In Social research methods: Quanlitative and quantitative approaches (6th ed.), (pp. 79-104), Boston: Pearson Education Inc.

Oflaz, F., Meric, M., Yuksel, Ç., \& Ozcan, C. T. (2011). Psychodrama: an innovative way of improving self-awareness of nurses. Journal of Psychiatric and Mental Health Nursing, 18(7), 569-575. https://doi.org/10.1111/j.1365-2850.2011.01704.x

Oon, P. P. (2010). Playing with Gladys: A case study integrating drama therapy with behavioural interventions for the treatment of selective mutism. Clinical Child Psychology and Psychiatry, 15(2), 215-230. https://doi.org/10.1177/1359104509352892

Oparah, Julia C. (2012). "Feminism and the (Trans) Gender Entrapment of Gender Nonconforming Prisoners.” UCLA Women's Law Journal, 18 (2).

Orkibi, H., Bar, N., \& Eliakim, I. (2014). The effect of drama-based group therapy on aspects of mental illness stigma. The Arts in Psychotherapy, 41(5), 458-466. https://doi.org/10.1016/j.aip.2014.08.006 
Pietkiewicz, I. \& Smith, J.A. (2012) A practical guide to using Interpretative Phenomenological Analysis in qualitative research psychology. Psychological Journal, 18(2), 361-369.

Preston, S. \& Redgrift, L. (2017). Phenomenology as social work inquiry: Parallels and divergences with Anti-Oppressive research. In H. Parada \& S. Wehbi (Eds.). Reimagining anti-oppression social work research. Toronto: Canadian Scholars.

Rossiter, A. (2007). Revisiting the Use of Self: Questioning Professional Identities. Canada: Canadian Scholars Press'.

Rousseau, C., Benoit, M., Gauthier, M.-F., Lacroix, L., Alain, N., Viger Rojas, M., Bourassa, D. (2007). Classroom Drama Therapy Program for Immigrant and Refugee Adolescents: A Pilot Study. Clinical Child Psychology and Psychiatry, 12(3), 451-465. https://doi.org/10.1177/1359104507078477

Russo, N. F., \& Pirlott, A. (2006). Gender-Based Violence Concepts, Methods, and Findings. Annals of the New York Academy of Sciences, 1087(1), 178-205.

Saeed, H. (2015). Empowering Unheard Voices through "Theatre of the Oppressed": Reflections on the Legislative Theatre Project for Women in Afghanistan-Notes from the Field. Journal of Human Rights Practice, 7(2), 299-326. 
Sakamoto , I., \& Pitner, R. O. (2005). Use of Critical Consciousness in Anti-Oppressive Social Work Practice: Disentangling Power Dynamics at Personal and Structural Levels. British Journal of Social Work, 35, 435-452.

Shawyer, S. (2011). Activist Awareness in the Theatre of the Oppressed Classroom. Canadian Theatre Review 147, 12-17. University of Toronto Press. Retrieved July 3, 2018, from Project MUSE database.

Sheehy, E. (1999). Legal responses to violence against women in Canada. Canadian Women Studies, 19(1/2), 62-73. Retrieved from https://search-proquestcom.ezproxy.lib.ryerson.ca/docview/217459594/fulltext/C9630E5BACFC427CPQ/1?acc ountid=13631

Smith, L. T. (2012). Research adventures on Indigenous lands. In decolonizing methodologies: Research and Indigenous peoples (2nd ed) (pp. 81-97). London \& New York: Zed Books Ltd.

Sokoloff, N. J., \& Dupont, I. (2005). Domestic Violence at the Intersections of Race, Class, and Gender. Violence Against Women, 11(1), 38-64.

Sommer, M., Muñoz-Laboy, M., Williams, A., Mayevskaya, Y., Falb, K., Abdella , G., \& Stark , L. (2018). How gender norms are reinforced through violence against adolescent girls in two conflict-affected populations. Child Abuse \& Neglect, 79, 154-163. 
Stahl, S. (2018). Acting Out to Call In: Practicing Theatre of the Oppressed With High School Students. The Educational Forum , 82, 369-373.

Statistics Canada. (2013). Measuring violence against women: Statistical trends. Canadian Centre for Justice Statistics, 3-120.

Strega, Susan. (2005). The view from the post-structural margins: Epistemology and methodology reconsidered, In S. Strega\& L. Brown (Eds.), Research as Resistance: Revisitng critical, Indigenous, and anti-oppressive approaches (2nd edition)(pp.119152). Toronto: Canadian Scholars' Press.

Suzack, C. (2015). Indigenous Feminisms in Canada. Nordic Journal of Feminist and Gender Research, 23(4), 261-274. doi: 10.1080/08038740.2015.1104595

Taylor, J. (2011). The intimate insider: Negotiating the ethics of friendship when doing insider research. Qualitative Research, 11(1), 3-22.

Terry, G., \& Hoare , J. (Eds.). (2007). Gender-based Violence . England : Oxfam GB.

Testoni, I., Armenti, A., Ronconi, L., Verdi, S., Wieser, M., Bucuta, M., Tarashoeva, G. (2015). Developing spontaneity and well-being in women victims of domestic violence. $\mathrm{La}$ Camera Blu. Rivista Di Studi Di Genere, O(11). https://doi.org/10.6092/1827-9198/2824 
UNFPA , \& WAVE. (2011). Strengthening Health System Responses to Gender-based Violence in Eastern Europe and Central Asia. Retrieved from http://www.healthgenderviolence.org/training-programme-for-health-care-providers/facts-on-gbv/defininggender-based-violence/21

Vinthagen, S., \& Johansson, A. (2013). "Everyday Resistance": Exploration of a Concept and its Theories. Resistance Studies Magazine, 2013(1), 1-46. Retrieved from http://resistancejournal.org/wp-content/uploads/2016/04/Vinthagen-Johansson-2013-Everydayresistance-Concept-Theory.pdf

Watts, C., \& Zimmerman, C. (2002). Violence against women: global scope and magnitude. The Lancet, 359, 1232-1237. Retrieved from http://www.religionscell.com/wpcontent/uploads/2013/03/violence-against-women-global-scope-and-magnitude.pdf

Wong, H., \& Ying Yee, J. (2010). An Anti-Oppression Framework for Child Welfare in Ontario. Ontario Child Welfare Anti-Oppression Roundtable.

World Health Organization, (2017). Violence against women. Retrieved from http://www.who.int/mediacentre/factsheets/fs239 